\title{
Avaliação teórico-experimental da resistência à compressão de concretos através de ensaios não destrutivos
}

\section{Theoretical and experimental evaluation of compressive strength of concretes through nondestructive tests}

\author{
Lucas Fadini Favarato ${ }^{1}$, Carlos Vinícius Soares do Rosário ${ }^{1}$, \\ João Pedro de Carvalho Alzuguir ${ }^{1}$, Matheus Abreu Kerkoff ${ }^{1}$, \\ Tarek Zogheib Aoun ${ }^{1}$, Geilma Lima Vieira ${ }^{1}$
}

\footnotetext{
${ }^{1}$ Laboratório de Ensaios em Materiais de Construção - LEMAC - CT/UFES - Campus Goiabeiras, CEP: 29075-910, Vitória, ES, Brasil.

e-mail: lucasffavarato@gmail.com, carlosvinicius360@gmail.com, joao.alzuguir@gmail.com, mkerkoff1@gmail.com, tarekzogheibaoun@hotmail.com, geilma.vieira@gmail.com
}

\begin{abstract}
RESUMO
Na avaliação de estruturas degradadas é comum a necessidade de se determinarem propriedades mecânicas de estruturas de concreto sem dispor dos dados de projeto. Propriedades como resistência à compressão e módulo de elasticidade, por exemplo, são importantes nessa análise. No entanto, a extração de testemunhos para avaliação laboratorial dos parâmetros de interesse, embora possível do ponto de vista teórico, nem sempre é uma alternativa viável em campo, seja por limitações de tempo, orçamento ou do próprio elemento estrutural. Neste contexto, a opção por ensaios não destrutivos é uma possibilidade que fornece com razoável precisão as informações desejadas. Na literatura, são obtidas formulações matemáticas que correlacionam de forma direta o índice esclerométrico e a velocidade de propagação das ondas ultrassônicas, com resistência à compressão e com módulo de elasticidade. Este trabalho comparou os resultados teóricos com experimentais, por intermédio de ensaios em 26 corpos-de-prova de concretos da Grande Vitória, com diferentes dosagens, tipos de cimento e idades, tendo como parâmetro base a resistência à compressão do concreto. Dessa forma, as conclusões deste estudo apontam para a existência de uma correlação entre os resultados obtidos com os ensaios não destrutivos e os experimentais.
\end{abstract}

Palavras-chave: resistência à compressão; ultrassom; esclerometria; ensaios não destrutivos.

\begin{abstract}
When evaluating degraded structures, it's common the need to determine mechanical properties of concrete structures with no project data. Properties such as compressive strength and modulus of elasticity, for example, are significant in this analysis. However, although it's possible to extract concrete samples for laboratory evaluations of parameters of interest, from the theoretical point of view, this is not always achievable when dealing with field activities, due to time limitations, budget restraints or even the structural restrictions from the element itself. In this sense, the preference for nondestructive methods is a possibility which provides, with reasonable accuracy, the needed information regarding the required mechanical properties. It's possible to find in the literature mathematical expressions that directly correlate sclerometrical index (or rebound index) and the ultrasonic pulse velocity to compressive strength and to the elastic modulus. Therefore, this work compared the theoretical results to the experimental ones, obtained through 26 specimens from the concrete used in Grande Vitoria, with different compositions and ages, based on this materials' compressive strength. Thus, this study's conclusions verified the existence of a correlation among the results obtained from nondestructive and experimental tests.
\end{abstract}

Keywords: compressive strength; ultra-sound; hammer test; nondestructive tests. 


\section{INTRODUÇÃO}

O concreto é, seguramente, o material mais disseminado no contexto da construção civil brasileira. Afinal, apresenta elevados índices de resistência à compressão e, juntamente com o aço, constitui excelente material para uso em estrutura de edificações. Dessa forma, torna-se preponderante para a segurança e para a estabilidade estrutural a realização de ensaios que comprovem e que validem seus parâmetros de aceitação.

Os ensaios de resistência à compressão têm como objetivo assinalar eventuais divergências na qualidade do concreto desde sua dosagem até a sua composição, tendo em vista que a resistência à compressão característica, $\mathrm{f}_{\mathrm{ck}}-$ valor tal que exista uma probabilidade de $5 \%$ em serem obtidas resistências inferiores ao mesmo - é o parâmetro que norteia o dimensionamento de um elemento estrutural. Assim, quanto melhor o controle de qualidade do material, maiores serão as chances de que o comportamento estrutural do elemento ao longo dos anos esteja de acordo com as diretrizes de projeto.

À vista disso, ressalta-se que o ensaio destrutivo para avaliação da resistência de corpos de prova cilíndricos, contemplado na ABNT NBR 5739 [1], constitui o método mais utilizado para se determinar a resistência característica do concreto. Tal teste consiste em moldar um corpo-de-prova cilíndrico de concreto, no instante da concretagem, de acordo com a norma ABNT NBR 5738 [2] e, após 28 dias de cura, romper essa amostra em uma prensa mecânica. $\mathrm{O}$ valor calculado é o $\mathrm{f}_{\mathrm{c} 28}$ do concreto utilizado - resistência à compressão aos 28 dias, que será parâmetro para determinação da resistência à compressão característica estimada de projeto, segundo a ABNT NBR 12655 [3].

No controle tecnológico de concretos, a formação de lotes de corpos-de-prova é elementar para o controle da qualidade e da resistência de elementos recém-moldados, permitindo a determinação precisa da resistência característica à compressão nas idades especificadas pelo projetista estrutural. Este procedimento, embora simples, exige a moldagem de um mínimo de 6 exemplares para concretos de classes até C50 e de 12 exemplares para concretos de classes superiores a $\mathrm{C} 50$ de algumas betonadas, quando se utiliza amostragem parcial, em conformidade com a ABNT NBR 12655 [3]. Quando se opta pelo controle estatístico por amostragem total, torna-se necessário amostrar todas as amassadas de concreto para então determinar o $\mathrm{f}_{\mathrm{ck}}$ estimado.

Por outro lado, quando é preciso avaliar o $\mathrm{f}_{\mathrm{cm}}$ de um elemento além dos 28 dias, por exemplo, recorrese à extração de testemunhos de concreto da estrutura para realizar o ensaio de compressão axial, prática nem sempre tão adequada, uma vez que se trata de um procedimento oneroso por envolver a mobilização de equipamentos, além de poder comprometer a integridade estrutural do elemento, de acordo com PALACIOS [4]. Nesse contexto, a opção por ensaios não destrutivos oferece vantagens significativas no tocante à velocidade de execução, aos custos reduzidos e à ausência de danos impostos à estrutura, uma vez que é dispensada a remoção de amostras para posterior ensaio laboratorial. Além disso, PALACIOS [4] ainda acrescenta que um maior volume de ensaios pode ser realizado, contribuindo para maior abrangência na investigação e possibilidade de verificar a homogeneidade de concretos já executados.

O principal objetivo dos ensaios não destrutivos, neste contexto, é a estimativa da resistência à compressão do concreto para subsequente avaliação de capacidade estrutural. Vale lembrar que estes ensaios não aferem de forma direta este parâmetro, mas outras propriedades do concreto as quais podem ser relacionadas de modo experimental a tal propriedade (TAY e TAMT apud PALACIOS [5]).

$\mathrm{Na}$ literatura, é possível encontrar diversas referências em que a resistência à compressão $\left(\mathrm{f}_{\mathrm{cm}}\right)$ do concreto em diferentes idades é correlacionada a dados provenientes de ensaios não destrutivos. PALACIOS [4] avaliou concretos de resistências características nominais de 30, 40 e 50 MPa na região de Brasília e visou à determinação da resistência à compressão pelos ensaios não destrutivos de esclerometria, velocidade de propagação da onda ultrassônica e penetração de pino. A variabilidade dos resultados foi avaliada e curvas experimentais foram elaboradas para avaliação do $\mathrm{f}_{\mathrm{cm}}$. Constatou-se que concretos de menores resistências apresentaram maior variabilidade que aqueles de alta resistência.

CÂMARA [6] desenvolveu um modelo matemático para avaliar a resistência à compressão dos concretos de 20, 25 e 30 MPa da Grande Florianópolis, aos 28 dias, a partir de leituras de velocidade de propagação de onda ultrassônica e do índice esclerométrico. Os resultados do ensaio de compressão dos corpos de prova permitiram elaborar curvas relacionando parâmetros de ensaios não destrutivos ao $\mathrm{f}_{\mathrm{cm}}$, resistência média do concreto. Posteriormente, testes foram conduzidos em obras que utilizaram as mesmas misturas de concreto a fim de validar a correlação proposta.

MACHADO et al. [7] propuseram curvas de correlação experimentais para a obtenção do módulo de elasticidade e da resistência à compressão de concretos moldados por concreteiras no Rio de Janeiro. Os concretos tinham resistências nominais de $25 \mathrm{MPa}$ ou $30 \mathrm{MPa}$, com variadas relações água/cimento e caracterís- 
ticas petrográficas do agregado graúdo. Foram realizados os ensaios de velocidade de propagação da onda ultrassônica, esclerometria, penetração de pino, resistência à compressão e módulo de elasticidade em concretos com idades de 3, 7, 14, 28 e 90 dias. Os autores concluíram que o ensaio de esclerometria levou à melhor avaliação da resistência à compressão, cuja acurácia foi melhorada com a combinação ao ensaio da penetração de pino. Por outro lado, o módulo de elasticidade pode ser mais bem estimado pelo ensaio de velocidade de propagação das ondas ultrassônicas.

IRRIGARAY et al. [8] investigaram experimentalmente de uma correlação entre velocidade do pulso ultrassônico (VPU) e resistência à compressão do concreto. Foram testadas misturas de concreto com relações água/cimento de 0,48, 0,55 e 0,64, com diferentes volumes de pasta. Para cada relação a/c e idades diferentes, ensaios de resistência à compressão e VPU em corpos de prova de pasta e argamassa foram realizados, o que comprovou a existência de uma relação única entre tais grandezas, com aplicabilidade a diversas misturas.

Neste contexto, o presente trabalho tem como objetivo estabelecer uma comparação entre as resistências características à compressão de concretos variados da região da Grande Vitória, ES, obtidas experimentalmente, e aquelas advindas de formulações teóricas e empíricas baseadas na velocidade de propagação da onda ultrassônica no concreto - padronizado pela ABNT NBR 8802 [9] - ou o índice esclerométrico - padronizado pela ABNT NBR 7584 [10], por meio de ensaios não destrutivos preconizados por normas brasileiras.

\section{MATERIAIS E MÉTODOS}

\subsection{Comportamento mecânico do concreto}

A resistência à compressão é um dos principais parâmetros de projeto para o dimensionamento de estruturas, tendo influência de diversos fatores, entre os quais se destacam o consumo de água e cimento, o tipo e forma dos agregados, as condições de cura, a velocidade de aplicação da carga, a duração do carregamento, a idade em que são feitas as medições (efeito do envelhecimento) e a forma e dimensões do corpo de prova utilizado no ensaio [11].

PACHECO et al. [12] acrescentam que as relações tensão x deformação no concreto não são lineares, em decorrência de sua natureza visco-elástica e de sua heterogeneidade. Diferentemente de materiais elásticos homogêneos, como os aços, a lei de Hooke não é válida e nem sempre há proporcionalidade entre tensão e deformação.

MEHTA e MONTEIRO [13] ressaltam que nem mesmo a deformação sob carregamentos instantâneos é diretamente proporcional à tensão, mantendo deformações plásticas depois de cessada a ação. Antes mesmo de entrar em carga, já existem microfissuras na matriz de transição entre agregado e pasta de cimento, que dependem das condições de cura, das características da exsudação e da própria resistência da zona de transição. Quando o carregamento é aplicado em concretos convencionais, é o agregado quem absorve integralmente as tensões e, à medida que ele se deforma, a carga é transferida para a pasta de cimento, surgindo as primeiras fissuras, que serão tanto maiores quanto maior a tensão aplicada [14], como se observa na Figura 1. 


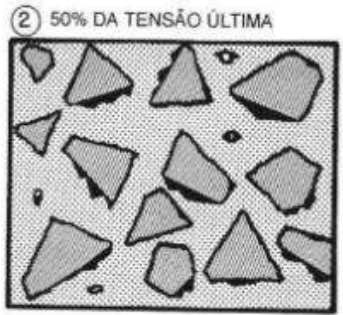

(1) 30\% DA TENSÃO ÚLTIMA

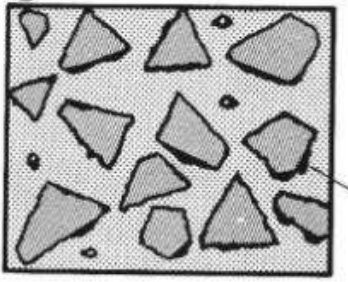

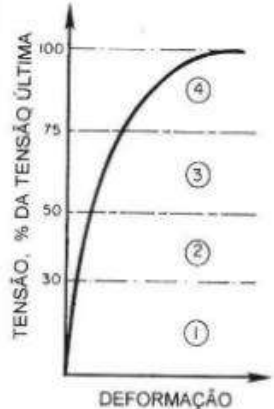

MICROFISSURAS NA ZONA DE TRANSIÇÁO
(4) TENSÃO DE RUPTURA

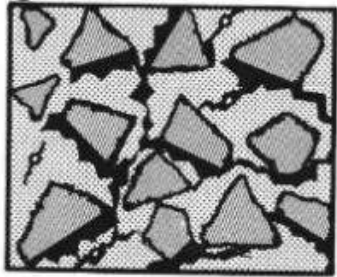

(3) $75 \%$ DA TENSÄO ÚLTIMA

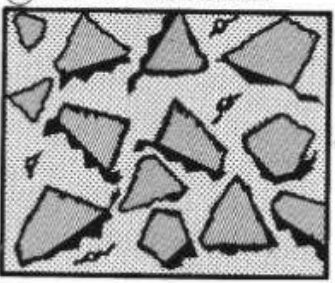

Figura 1: Comportamento tensão-deformação do concreto na compressão axial (Fonte: Mehta e Monteiro [13]).

Por outro lado, diversas simplificações são adotadas para dimensionamento de elementos estruturais, tanto para estados limites últimos como de serviço. A ABNT NBR 6118 [15] admite um comportamento linear para o concreto (Figura 2), obedecendo à Lei de Hooke, para tensões de compressão inferiores a $0,5 f_{\mathrm{cm}}$, limite de trabalho das peças de concreto.

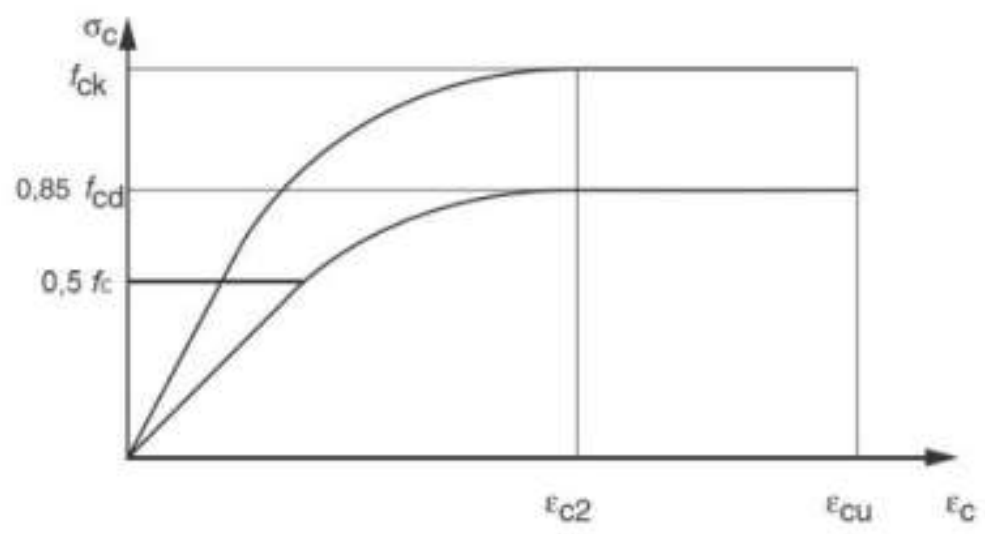

Figura 2: Diagrama tensão-deformação idealizado para o concreto (Fonte: adaptado de ABNT NBR 6118 [15]).

De acordo com BENETTI [16], o comportamento não linear do concreto e a forma como o carregamento é imposto ao corpo de prova levam à definição de dois tipos de módulos de elasticidade, isto é, razão entre tensão e deformação no trecho elástico:

a) Estático (MEE): obtido através do ensaio normalizado pela ABNT NBR 8522 [17], na qual a velocidade de carregamento permite deformações mais lentas no corpo de prova. Trata-se, portanto, de um ensaio destrutivo. De acordo com as tensões de referência para sua determinação, três subtipos podem ser definidos:

i. Módulo de elasticidade tangente inicial: obtido aos 28 dias de idade, representa a inclinação da curva tensão-deformação em sua origem. É o mais utilizado em projeto.

ii. Módulo de elasticidade secante: declividade da reta que passa pelos pontos cujas ordenadas são $0,5 \mathrm{MPa}$ e $40 \%$ da tensão de ruptura.

iii. Módulo de elasticidade cordal: inclinação de uma reta que passa por dois pontos quaisquer da curva tensão-deformação. É pouco utilizado em projeto.

b) Dinâmico (MED): obtida através de ensaios não destrutivos. Como a velocidade de carregamento é rápida, as deformações no concreto por fluência não têm condições de ocorrer, resultando em deformações instantâneas pequenas. Como consequência, o valor obtido é cerca de $20 \%$, 30\% e 40\% 
maior que o módulo de elasticidade estático de concretos de alta, média e baixa resistência, respectivamente. Além disso, este valor é afetado por diversos fatores, como umidade no momento do ensaio e fissuração no concreto. MEHTA e MONTEIRO [13] complementam que este parâmetro pode ser aproximado pelo módulo de elasticidade tangente inicial. VASCONCELOS e GIAMMUSSO [18] também sugerem uma correlação entre valores estático e dinâmico, com base no Código Britânico CP 110/72 [19], desde que o consumo de cimento seja igual ou inferior a $500 \mathrm{~kg} / \mathrm{m}^{3}$.

\subsection{Programa experimental}

O planejamento experimental deste trabalho envolveu métodos de avaliações destrutivos, mediante o ensaio de resistência à compressão axial em corpos de prova cilíndricos de concreto, e não destrutivos, representados pelos ensaios de velocidade de propagação de onda ultrassônica e dureza superficial do concreto, ambos normatizados pela ABNT. Para esta amostra foram considerados um total de 26 corpos de prova de concreto provenientes de obras executadas na região da Grande Vitória-ES.

Os ensaios de determinação da velocidade de propagação de onda ultrassônica, avaliação da dureza superficial pelo esclerômetro de reflexão e resistência à compressão axial de corpos de prova foram realizados a fim de correlacionar os resultados obtidos de ensaios não destrutivos com a resistência à compressão real. Vale ressaltar que a determinação do índice esclerométrico foi realizada após o ensaio ultrassom, a fim de evitar que os impactos pontuais do esclerômetro provocassem algum tipo de perturbação na amostra.

Num primeiro momento, realizou-se a verificação das condições geométricas (altura x diâmetro) de todos os corpos de prova. Os diâmetros foram aferidos duas vezes - uma em cada extremidade do corpo de prova e defasados de $90^{\circ}$, sendo o valor final obtido por média aritmética simples (Figura 3).

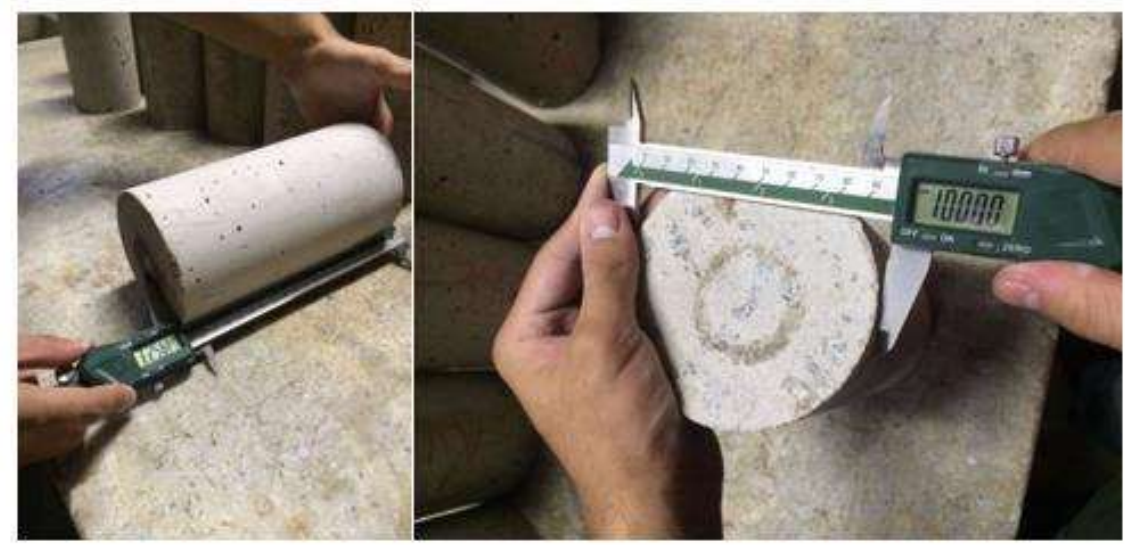

Figura 3: Medição de altura e diâmetro dos corpos de prova (Fonte: autores).

Na sequência, pesaram-se dos corpos de prova em balança digital, com precisão de 0,1g (Figura 4), para posterior determinação da massa específica do concreto, parâmetro necessário para avaliação do módulo de elasticidade dinâmico da amostra. 


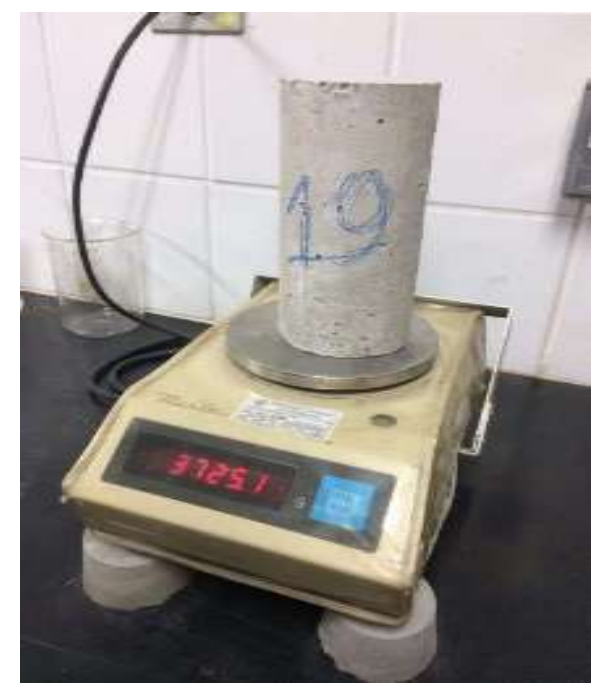

Figura 4: Pesagem do corpo de prova $\mathrm{n}^{\circ} 19$ (Fonte: autores).

\subsubsection{Determinação da velocidade de propagação de onda ultrassônica}

De acordo com a ABNT NBR 8802 [9], o objetivo do ensaio de determinação da velocidade de propagação de onda ultrassônica é determinar a velocidade de propagação de ondas longitudinais, obtidas por pulsos ultrassônicos, através de um componente de concreto.

Os corpos de prova foram previamente preparados, conforme especificações da norma ABNT NBR 8802 [9], de modo que:

- As superfícies a serem ensaias sejam planas, lisas e isentas de sujeira;

- Os corpos-de-prova tenham as mesmas condições de composição e umidade relativa.

A calibragem do aparelho responsável pela emissão das ondas ultrassônicas foi realizada conforme metodologia da norma ABNT NBR 8802 [9]. Para cada leitura, foi necessário informar ao aparelho a distância percorrida pelos pulsos, que correspondeu à própria altura do corpo-de-prova.

Uma fina camada de acoplante (gel) foi aplicada nas faces do corpo-de-prova e dos transdutores. Em seguida, estes foram posicionados entre as faces planas opostas da amostra, num arranjo denominado transmissão direta. Esta metodologia foi escolhida em conformidade com a ABNT NBR 8802 [9] por ser mais recomendada na determinação da velocidade de propagação de ondas através de um material uma vez que, desta maneira, os transdutores se posicionam em faces opostas e as ondas são recebidas com maior intensidade (Figura 5). 


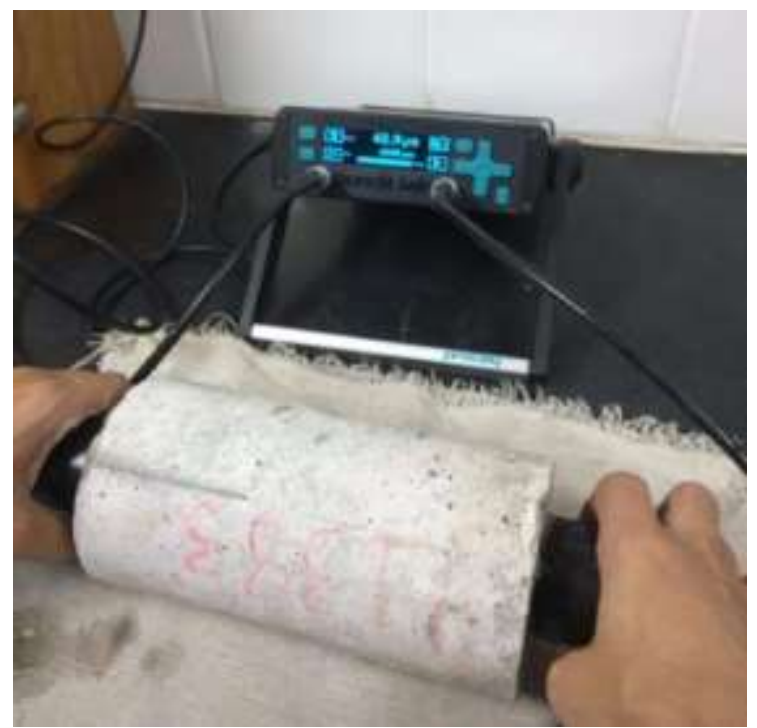

Figura 5: Aparelho de ultrassom utilizado no ensaio (Fonte: autores).

O aparelho forneceu a velocidade da onda e seu tempo de percurso. Foram computadas as leituras para cada corpo de prova.

\subsubsection{Avaliação da dureza superficial pelo esclerômetro de reflexão}

De acordo com SOUZA et al. [20], a esclerometria é um ensaio capaz de estimar a dureza superficial de uma peça estrutural e também a qualidade do concreto endurecido. Um martelo se choca com a área de ensaio e retorna uma leitura denominada de índice esclerométrico, fornecido diretamente pelo aparelho e correspondente ao seu número de recuo (ABNT NBR 7584 [10]). Assim, é feita uma correlação do índice esclerométrico com a resistência do material através de uma correlação fornecida pelo fabricante.

Segundo a ABNT NBR 7584 [10], a superfície de concreto a ser analisada deve ser seca ao ar, limpa, uniforme e, preferencialmente, plana. Neste estudo, a superfície em que foi realizado o ensaio foi a área lateral dos corpos de prova previamente utilizados para determinação da velocidade de propagação de onda ultrassônica.

É recomendado que o teste seja realizado 16 vezes por área, espaçadas de 30 milímetros entre si. Entretanto, a fim de adequar o ensaio ao caso estudado, efetuaram-se 3 impactos espaçados de 30 milímetros entre si, por corpo de prova: um na extremidade inferior, um no meio e outro na extremidade superior. Cabe destacar, ainda, que o esclerômetro foi previamente calibrado segundo a metodologia da norma ABNT NBR 7584 [10], utilizando uma bigorna de aço.

Em seguida, com o corpo de prova fixado à prensa mecânica, o ensaio de esclerometria foi realizado, mantendo o esclerômetro de reflexão sempre ortogonal à área de teste (Figura 6 e Figura 7). 


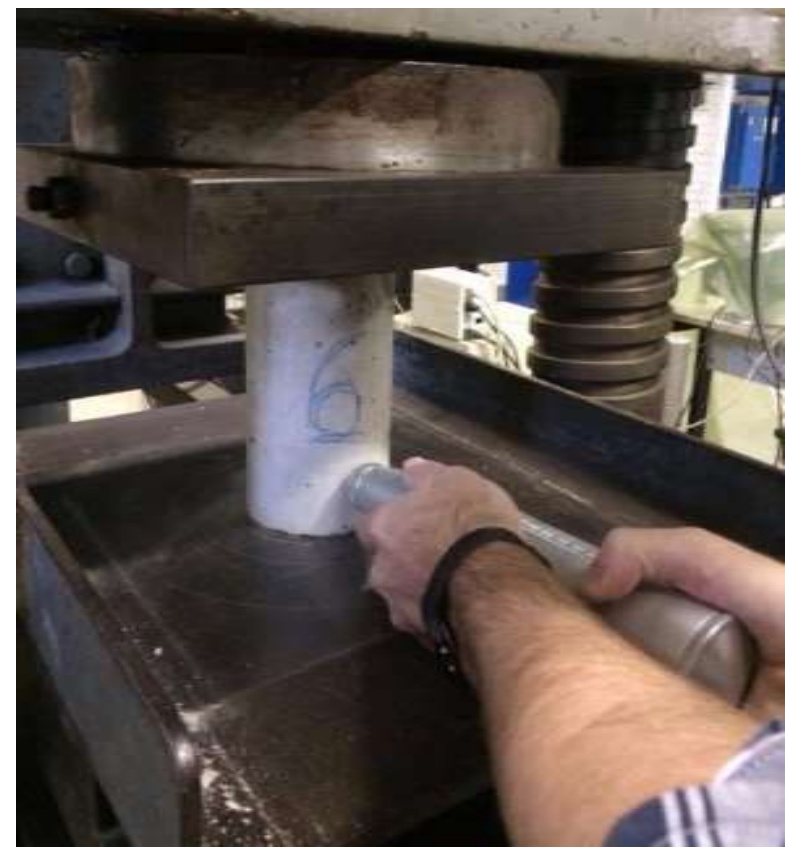

Figura 6: Realização do ensaio de esclerometria no corpo de prova cilíndrico (Fonte: autores).

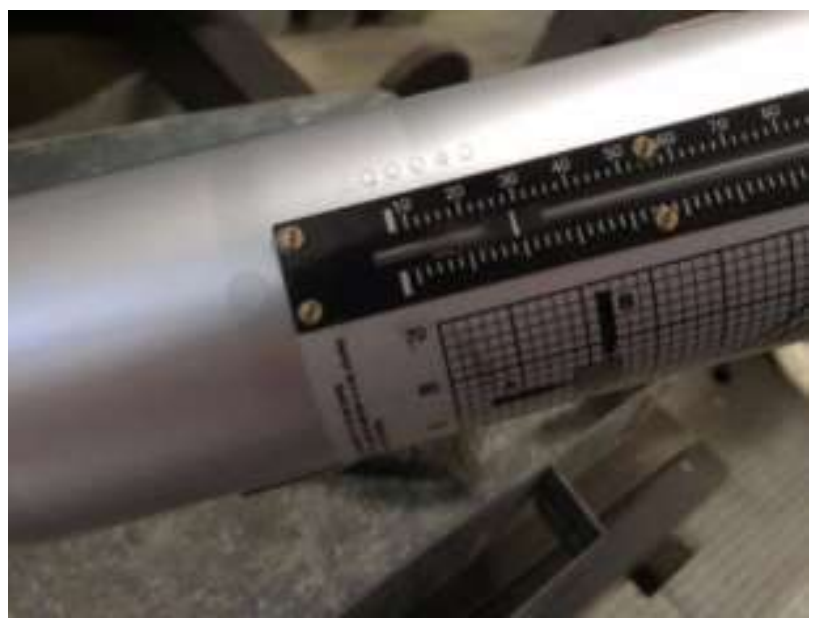

Figura 7: Leitura do índice esclerométrico (Fonte: autores).

A resistência à compressão do corpo de prova foi estimada, por fim, através da curva fornecida pelo fabricante do esclerômetro de impacto (Figura 8). 


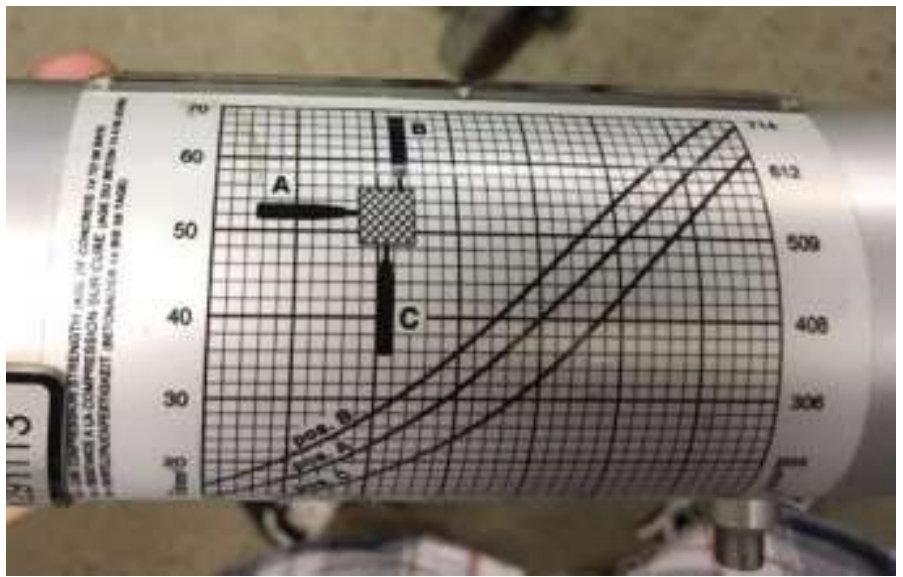

Figura 8: Correlação entre $\mathrm{f}_{\mathrm{cm}} \mathrm{e}$ índice esclerométrico fornecida pelo fabricante (Fonte: autores).

\subsubsection{Ensaio de resistência à compressão axial de corpos de prova cilíndricos}

Este procedimento tem por objetivo determinar a resistência à compressão axial de corpos de prova cilíndricos, a fim de compara-la à resistência obtida por correlações através dos ensaios de esclerometria e de ultrassom.

O ensaio de compressão axial foi realizado após o ensaio de esclerometria. Cada corpo de prova foi posicionado de forma que seu eixo coincidisse com o da máquina, garantindo que a resultante das forças passasse pelo seu centro geométrico, conforme estabelecido pela ABNT NBR 5739 [1] (Figura 9 e Figura 10).

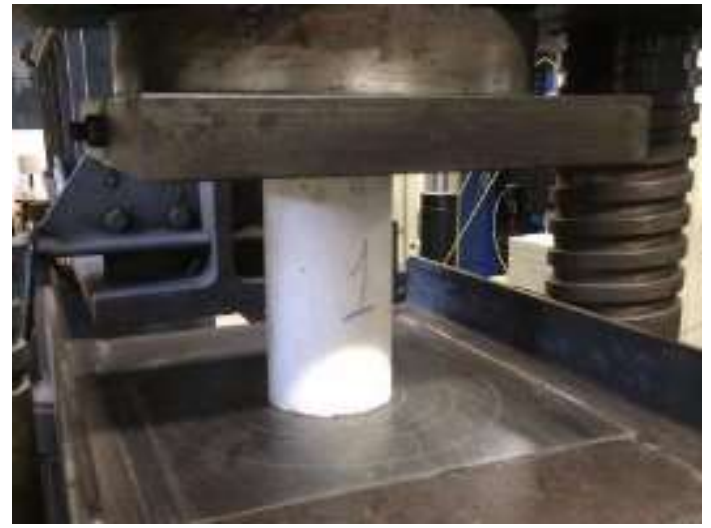

Figura 9: Ensaio de compressão axial no corpo de prova 1 (Fonte: autores).

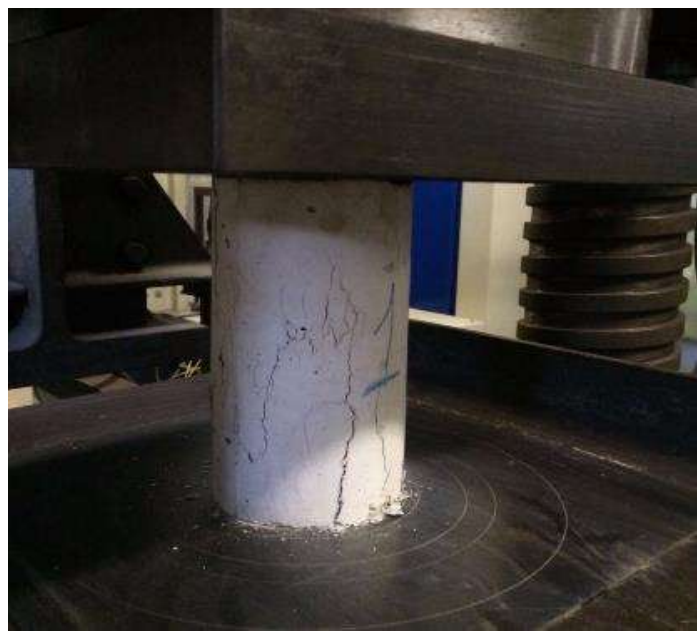

Figura 10: Corpo de prova 1 após ruptura (Fonte: autores). 
Foram computadas as leituras da carga de ruptura de cada corpo de prova, em toneladas-força, fornecidas pela prensa hidráulica. De posse de suas dimensões, calculou-se a tensão de ruptura, em MPa.

\subsection{Modelos para avaliação da resistência à compressão pelo ensaio de ultrassom}

Em conformidade com a ASTM C597-02 [21], o módulo de elasticidade dinâmico do concreto ( $\left.E_{\mathrm{d}}\right)$, em MPa, pode ser calculado por meio da Equação (1):

$$
E_{d}=V^{2} \rho\left[\frac{(1+\mu)(1-2 \mu)}{(1-\mu)}\right]
$$

Sendo:

$\mu$ - coeficiente de Poisson (adotado como 0,2 em concordância com a ABNT NBR 6118 [15]);

$V$ - velocidade de propagação do som no concreto $(\mathrm{km} / \mathrm{s})$;

$\rho$ - densidade do material $\left(\mathrm{kg} / \mathrm{m}^{3}\right)$.

O módulo de elasticidade estático inicial, por sua vez, pode ser obtido por correlação matemática baseada em modelos conhecidos e aceitos no meio técnico. Posteriormente, é possível relacioná-lo com a resistência característica à compressão através da Equação (2), preconizada na ABNT NBR 6118 [15]. O coeficiente $\alpha_{\mathrm{E}}$ leva em conta a influência do tipo de agregado graúdo, assumindo os valores de 1,2 para basalto e diabásio, 1,0 para granito e gnaisse, 0,9 para calcário e 0,7 para arenito.

$$
E_{c i}=\left\{\begin{array}{c}
5600 \alpha_{\mathrm{E}} \sqrt{\mathrm{f}_{\mathrm{ck}}}, \quad \mathrm{f}_{\mathrm{ck}} \leq 50 \mathrm{MPa} \\
21500 \alpha_{\mathrm{E}}\left(\frac{\mathrm{f}_{\mathrm{ck}}}{10}+1,25\right)^{\frac{1}{3}}, \quad \mathrm{f}_{\mathrm{ck}} \geq 55 \mathrm{MPa}
\end{array}\right.
$$

Serão apresentados quatro modelos utilizados para avaliação da resistência à compressão do concreto através do referido ensaio. Dois deles são teóricos, baseados na combinação das Equações (1) e (2), enquanto os outros dois são experimentais, encontrados na literatura.

\subsubsection{Modelo 1}

Conforme ressaltado anteriormente, MEHTA e MONTEIRO [13] indicam a possibilidade de considerar o módulo de elasticidade dinâmico (MED) igual ao módulo de elasticidade estático (MEE) tangente inicial. Com isso, a velocidade de propagação das ondas ultrassônicas no concreto pode ser relacionada à resistência característica do concreto à compressão, comparando as Equações (1) e (2), conforme Equação (3).

$$
f_{c k}=\left\{\begin{array}{c}
{\left[\frac{v^{2} \rho}{5,6 \alpha_{\mathrm{E}} 10^{9}} \frac{(1+\mu)(1-2 \mu)}{(1-\mu)}\right]^{2}, \quad v \leq 4281,63 \sqrt{\alpha_{\mathrm{E}}}} \\
10\left[\frac{\mathrm{v}^{2} \rho}{21,5 \alpha_{\mathrm{E}} 10^{9}} \frac{(1+\mu)(1-2 \mu)}{(1-\mu)}\right]^{3}-12,5, \quad \mathrm{v}>4281,63 \sqrt{\alpha_{\mathrm{E}}}
\end{array}\right.
$$

Adotando a massa específica do concreto como $2400 \mathrm{~kg} / \mathrm{m}^{3}$ e o coeficiente de Poisson como 0,2, conforme prescrições da ABNT NBR 6118 [15], e substituindo esses valores na Equação (3), a resistência à compressão pode ser calculada por:

$$
f_{c k}=\left\{\begin{array}{c}
\frac{14,88}{10^{14}}\left(\frac{v^{2}}{\alpha_{E}}\right)^{2}, \quad v \leq 4281,63 \sqrt{\alpha_{E}} \\
\frac{101,4}{10^{22}}\left(\frac{v^{2}}{\alpha_{E}}\right)^{3}-12,5, \quad v>4281,63 \sqrt{\alpha_{E}}
\end{array}\right.
$$

Para que a Equação (4) forneça resultados satisfatórios, a velocidade (v) deve ser utilizada em m/s. A 
consideração de basalto e diabásio como agregados graúdos fornece resultados condizentes com a realidade, uma vez que o $f_{\text {ck }}$ permaneceu entre 25 e $80 \mathrm{MPa}$ para a faixa de velocidades analisada. Por outro lado, quando se utiliza a curva referente ao arenito, os resultados ficam acima dos demais e são superiores a $100 \mathrm{MPa}$, o que é incoerente por ser uma rocha menos resistente e menos densa quando comparada ao basalto, ao diabásio, ao granito e à gnaisse. Este comportamento pode estar relacionado com a porosidade do agregado granítico. É sabido que o arenito possui uma alta porosidade que, consequentemente, absorve água. Com isso, ocorre um aumento da velocidade de propagação de onda ultrassônica. Vale, ainda, ressaltar que esta correlação não aborda de forma pontual a influência dos demais fatores relacionados à resistência à compressão dos concretos, como teor de cimento e relação água/cimento.

\subsubsection{Modelo 2}

Utilizando agora a correlação entre o MED e MEE sugerida por VASCONCELOS e GIAMMUSSO [18], baseada no Código Britânico CP 110/72 [19] e válida para consumo de cimento inferior a $500 \mathrm{~kg} / \mathrm{m}^{3}$, Equação (5), é possível estabelecer outra correlação entre velocidade de propagação de ondas ultrassônicas e resistência à compressão:

$$
\mathrm{E}_{\mathrm{ci}}=1,25 \mathrm{E}_{\mathrm{d}}-19000, \quad\left[\mathrm{E}_{\mathrm{ci}}\right]=\left[\mathrm{E}_{\mathrm{d}}\right]=\mathrm{MPa}
$$

Tomando o valor de $\mathrm{E}_{\mathrm{ci}}$ e $\mathrm{E}_{\mathrm{d}}$ em conformidade com a ABNT NBR 6118 [15] e com a ASTM C597-02 [21], respectivamente, chega-se à Equação (6).

$$
\begin{aligned}
& \mathrm{f}_{\mathrm{ck}}=\left\{\begin{array}{c}
{\left[\frac{1,25 \mathrm{v}^{2} \rho(1+\mu)(1-2 \mu)}{5,6 \alpha_{\mathrm{E}}(1-\mu) 10^{9}}-\frac{190}{56 \alpha_{\mathrm{E}}}\right]^{2}, \quad \mathrm{v} \leq \mathrm{a}} \\
10\left[\frac{\mathrm{v}^{2} \rho(1+\mu)(1-2 \mu)}{17,2 \alpha_{\mathrm{E}}(1-\mu) 10^{9}}-\frac{190}{215 \alpha_{\mathrm{E}}}\right]^{3}-12,5, \quad \mathrm{v}>a
\end{array}\right. \\
& a=1000\left(\frac{396 \alpha_{E}}{27}+\frac{190}{27}\right)^{\frac{1}{2}}
\end{aligned}
$$

Em que:

$\mathrm{v}$ - velocidade de propagação das ondas ultrassônicas $(\mathrm{m} / \mathrm{s})$;

$\rho$ - densidade do concreto (2400 kg/m³, conforme ABNT NBR 6118 [15]);

$\mu$ - coeficiente de Poisson (0,2, conforme ABNT NBR 6118 [15]);

$\mathrm{f}_{\mathrm{ck}}-$ resistência à compressão característica do concreto $(\mathrm{MPa})$;

A correlação traduzida pela Equação (6) fornece resultados melhores do ponto de vista prático do que aqueles obtidos pela Equação (6), apesar de os valores do $f_{c k}$ de concretos com agregado de rocha arenítica permanecerem elevados. A comparação dos dados fornecidos pelas Equações (4) e (6) está mostrada na Figura 11, em que VG indica a correlação de VASCONCELOS e GIAMMUSSO [18] e MM aquela de MEHTA e MONTEIRO [13]. 


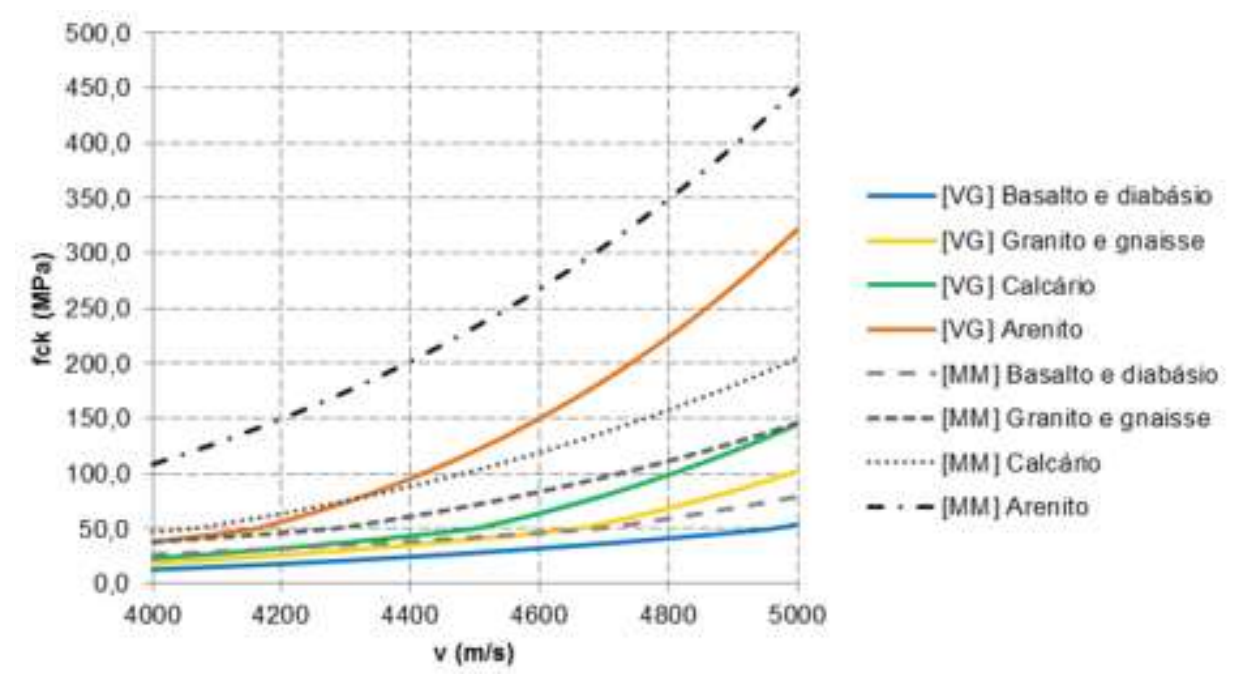

Figura 11: Comparação dos modelos representados pelas das Equações (4) e (6) (Fonte: adaptado de ABNT NBR 6118 [15], ASTM C597-02 [21], MEHTA e MONTEIRO [13] e VASCONCELOS e GIAMMUSSO [18]).

\subsubsection{Modelo 3}

PALACIOS [4] propôs uma equação exponencial que permite correlacionar a resistência à compressão com a velocidade de propagação da onda ultrassônica, conforme Equação (7). A fórmula apresentada deve ser utilizada dentro dos limites estabelecidos pela autora. Além disso, o material aglomerante é do tipo CP V ARI, com agregados graúdos (brita 0 e brita 1 ) de rocha calcária e agregados miúdos de origem calcária e quartzito, bem como aditivo plastificante polifuncional de nome comercial Bf-10. Os concretos foram dosados em laboratório, com relações água cimento de 0,51, 0,60 e 0,72.

$$
\mathrm{f}_{\mathrm{cm}}=\frac{4 \mathrm{~V}^{6,9017}}{10^{24}}
$$

Em que:

$f_{c m}$ - Resistência média à compressão do concreto (MPa);

$V$ - Velocidade de propagação do som no concreto, $4100 \leq V \leq 4350(\mathrm{~m} / \mathrm{s})$.

\subsubsection{Modelo 4}

O último modelo, proposto por MACHADO et al. [7], propôs uma outra equação exponencial para relacionar a resistência à compressão com a velocidade de propagação da onda ultrassônica, conforme Equação (8). Os dados foram ajustados a partir de amostras em que as velocidades variaram entre 3700 e $4700 \mathrm{~m} / \mathrm{s}$.

$$
\mathrm{f}_{\mathrm{cm}}=0,036 \mathrm{~V}^{4,696}
$$

\section{Em que:}

$f_{c m}$ - Resistência média à compressão do concreto (MPa);

$V$ - Velocidade de propagação do som no concreto $(\mathrm{km} / \mathrm{s})$. 


\subsection{Modelos para avaliação da resistência à compressão pelo ensaio de esclerometria}

\subsubsection{Modelo 5}

A resistência à compressão de concretos obtida pelo ensaio de dureza superficial medida pelo esclerômetro de reflexão pode ser estimada por correlações empíricas fornecidas pelo próprio fabricante do aparelho. A curva, esboço da Equação (9), é obtida por uma linha de tendência referente ao ajuste experimental de dados fornecidos pelo fabricante do equipamento.

$$
\mathrm{f}_{\mathrm{c}}=0,0352 \mathrm{IE}^{1,9019}
$$

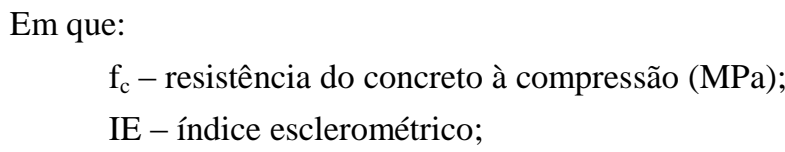

\subsubsection{Modelo 6}

O modelo experimental proposto por PALACIOS [4] sugere uma equação linear para correlacionar a resistência à compressão do concreto com o índice esclerométrico, conforme Equação (10).

$$
f_{c}=3,13 \mathrm{IE}-64,482
$$

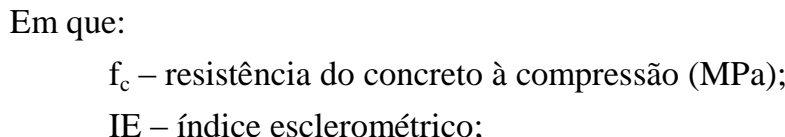

\subsubsection{Modelo 7}

O último modelo foi proposto por MACHADO et al. [7], os quais sugerem uma equação exponencial para correlacionar a resistência à compressão do concreto com o índice esclerométrico, conforme Equação (11).

$$
\mathrm{f}_{\mathrm{c}}=0,026 \mathrm{IE}^{2,044}
$$

Em que:

$\mathrm{f}_{\mathrm{c}}$ - resistência do concreto à compressão $(\mathrm{MPa})$;

IE - índice esclerométrico;

\section{RESULTADOS}

Para verificar a acurácia das correlações teóricas e empíricas apresentadas neste estudo, foram ensaiados 26 corpos de prova cilíndricos no Laboratório de Ensaios em Materiais de Construção (LEMAC) da Universidade Federal do Espírito Santo, cujas dimensões, obtidas com paquímetro digital, e massa estão indicadas na Tabela 1. 
Tabela 1: Dimensões, massas e massas específicas aparentes dos corpos de prova ensaiados (Fonte: autores).

\begin{tabular}{|c|c|c|c|c|c|c|c|c|}
\hline \multirow{2}{*}{ ID } & \multicolumn{3}{|c|}{ DIÂMETRO } & \multirow{2}{*}{$\begin{array}{l}\text { ALTURA } \\
H_{1}(\mathrm{~mm})\end{array}$} & \multirow{2}{*}{$\begin{array}{c}\text { MASSA } \\
m_{1}(g)\end{array}$} & \multirow{2}{*}{$\begin{array}{c}\begin{array}{c}\text { ÁREA } \\
\text { DA BASE }\end{array} \\
A\left(\mathrm{~cm}^{2}\right)\end{array}$} & \multirow{2}{*}{$\begin{array}{c}\text { VOLUME } \\
\text { V }\left(\mathrm{cm}^{3}\right)\end{array}$} & \multirow{2}{*}{$\begin{array}{c}\text { MASSA } \\
\text { ESPECÍFICA } \\
\rho\left(\mathbf{k g} / \mathbf{m}^{3}\right)\end{array}$} \\
\hline & $\begin{array}{c}D_{1} \\
(\mathrm{~mm})\end{array}$ & $\begin{array}{c}D_{2} \\
(\mathrm{~mm})\end{array}$ & $\begin{array}{c}D_{\text {med }} \\
(\mathrm{mm})\end{array}$ & & & & & \\
\hline CP1 & 100,74 & 100,58 & 100,66 & 196,28 & 3730,8 & 79,6 & 1562,0 & 2388,48 \\
\hline $\mathrm{CP} 2$ & 99,81 & 99,93 & 99,87 & 195,04 & 3697,1 & 78,3 & 1527,9 & 2419,79 \\
\hline CP3 & 99,53 & 99,93 & 99,73 & 195,22 & 3709,3 & 78,1 & 1525,0 & 2432,35 \\
\hline CP4 & 100,80 & 100,35 & 100,58 & 196,10 & 3715,2 & 79,4 & 1557,9 & 2384,70 \\
\hline CP5 & 100,12 & 101,29 & 100,71 & 195,73 & 3612,7 & 79,7 & 1559,0 & 2317,30 \\
\hline CP6 & 99,50 & 100,69 & 100,10 & 196,18 & 3701,2 & 78,7 & 1543,7 & 2397,58 \\
\hline CP7 & 99,73 & 99,98 & 99,86 & 197,00 & 3751,4 & 78,3 & 1542,8 & 2431,63 \\
\hline CP8 & 100,24 & 100,55 & 100,40 & 193,94 & 3699,6 & 79,2 & 1535,3 & 2409,76 \\
\hline CP9 & 99,89 & 100,05 & 99,97 & 194,86 & 3678,7 & 78,5 & 1529,5 & 2405,15 \\
\hline CP10 & 99,97 & 99,74 & 99,86 & 196,01 & 3654,8 & 78,3 & 1535,0 & 2380,98 \\
\hline CP11 & 99,88 & 100,00 & 99,94 & 195,38 & 3670,4 & 78,4 & 1532,7 & 2394,78 \\
\hline CP12 & 100,75 & 100,60 & 100,68 & 192,26 & 3757,8 & 79,6 & 1530,5 & 2455,34 \\
\hline CP13 & 100,97 & 101,64 & 101,31 & 191,58 & 3490,1 & 80,6 & 1544,2 & 2260,14 \\
\hline CP14 & 99,91 & 102,84 & 101,38 & 196,20 & 3833,7 & 80,7 & 1583,6 & 2420,85 \\
\hline CP15 & 101,99 & 100,79 & 101,39 & 198,71 & 3806,4 & 80,7 & 1604,4 & 2372,55 \\
\hline CP16 & 99,32 & 103,97 & 101,65 & 194,87 & 3652,4 & 81,1 & 1581,3 & 2309,78 \\
\hline CP17 & 101,37 & 100,70 & 101,04 & 196,83 & 3850,1 & 80,2 & 1578,1 & 2439,76 \\
\hline CP18 & 100,61 & 101,04 & 100,83 & 194,51 & 3644,2 & 79,8 & 1553,0 & 2346,57 \\
\hline CP19 & 101,41 & 98,48 & 99,95 & 193,93 & 3725,1 & 78,5 & 1521,4 & 2448,39 \\
\hline CP20 & 101,14 & 99,69 & 100,42 & 196,93 & 3584,4 & 79,2 & 1559,5 & 2298,36 \\
\hline CP21 & 100,35 & 101,55 & 100,95 & 192,47 & 3740,6 & 80,0 & 1540,5 & 2428,15 \\
\hline CP22 & 100,75 & 101,27 & 101,01 & 193,18 & 3804,7 & 80,1 & 1548,0 & 2457,76 \\
\hline CP23 & 100,50 & 100,13 & 100,32 & 187,84 & 3492,6 & 79,0 & 1484,6 & 2352,55 \\
\hline CP24 & 101,26 & 99,50 & 100,38 & 197,38 & 3776,4 & 79,1 & 1562,0 & 2417,63 \\
\hline CP25 & 100,82 & 99,95 & 100,39 & 191,69 & 3678,2 & 79,1 & 1517,1 & 2424,42 \\
\hline CP26 & 100,10 & 100,65 & 100,38 & 191,20 & 3468,5 & 79,1 & 1513,0 & 2292,52 \\
\hline
\end{tabular}

Os corpos de prova são provenientes de diversas obras executadas na região da Grande Vitória, com dosagens diferentes entre si, inclusive tipos de cimento. Porém, todos apresentam idade superior a 28 dias, momento em que o concreto atingiu $100 \%$ da resistência necessária para projeto $\left(\mathrm{f}_{\mathrm{c} 28}\right)$.

Após a determinação da massa específica, foram realizados os ensaios de ultrassom, esclerometria e resistência à compressão, nesta ordem, em conformidade com as respectivas normas técnicas, com as observações cabíveis. Os resultados estão apresentados na Tabela 2. 
Tabela 2: Resultados dos ensaios (Fonte: autores).

\begin{tabular}{|c|c|c|c|c|c|c|c|c|}
\hline \multirow{2}{*}{ ID } & \multirow{2}{*}{$\begin{array}{c}\text { ÁREA DA } \\
\text { BASE } \\
A\left(\mathrm{~cm}^{2}\right)\end{array}$} & \multirow{2}{*}{$\begin{array}{c}\text { CARGA DE } \\
\text { RUPTURA } \\
\mathbf{P} \text { (tf) }\end{array}$} & \multirow{2}{*}{$\begin{array}{c}\begin{array}{c}\text { RESISTÊNCIA } \\
\text { A } \\
\text { COMPRESSÃO }\end{array} \\
\mathrm{f}_{\mathrm{c}}(\mathrm{MPa}) \\
\end{array}$} & \multirow{2}{*}{$\begin{array}{c}\text { VELOCIDADE } \\
\text { DA ONDA } \\
v(\mathrm{~m} / \mathrm{s})\end{array}$} & \multicolumn{4}{|c|}{ ÍNDICE ESCLEROMÉTRICO } \\
\hline & & & & & $I E_{\text {med }}$ & $\mathrm{IE}_{1}$ & $\mathrm{IE}_{2}$ & $\mathrm{IE}_{3}$ \\
\hline CP1 & 79,6 & 26,600 & 32,8 & 4569 & 33 & 27 & 35 & 38 \\
\hline CP2 & 78,3 & 24,800 & 31,1 & 4545 & 29 & 28 & 28 & 32 \\
\hline CP3 & 78,1 & 25,400 & 31,9 & 4599 & 29 & 29 & 31 & 28 \\
\hline CP4 & 79,4 & 31,500 & 38,9 & 4569 & 32 & 34 & 35 & 28 \\
\hline CP5 & 79,7 & 29,200 & 36,0 & 4569 & 41 & 42 & 38 & 42 \\
\hline CP6 & 78,7 & 30,300 & 37,8 & 4569 & 27 & 28 & 24 & 29 \\
\hline CP7 & 78,3 & 25,100 & 31,4 & 4592 & 30 & 33 & 30 & 28 \\
\hline CP8 & 79,2 & 28,200 & 34,9 & 4575 & 26 & 23 & 28 & 28 \\
\hline CP9 & 78,5 & 31,900 & 39,9 & 4599 & 32 & 31 & 33 & 32 \\
\hline CP10 & 78,3 & 26,500 & 33,2 & 4135 & 31 & 29 & 32 & 31 \\
\hline CP11 & 78,4 & 29,400 & 36,8 & 4545 & 28 & 26 & 29 & 30 \\
\hline CP12 & 79,6 & 41,700 & 51,4 & 4694 & 42 & 42 & 42 & 42 \\
\hline CP13 & 80,6 & 33,000 & 40,2 & 4374 & 35 & 36 & 38 & 32 \\
\hline CP14 & 80,7 & 46,500 & 56,5 & 4734 & 42 & 42 & 42 & 41 \\
\hline CP15 & 80,7 & 47,000 & 57,1 & 4639 & 44 & 46 & 43 & 43 \\
\hline CP16 & 81,1 & 49,800 & 60,2 & 4545 & 42 & 43 & 42 & 42 \\
\hline CP17 & 80,2 & 48,000 & 58,7 & 4539 & 33 & 32 & 32 & 36 \\
\hline CP18 & 79,8 & 31,000 & 38,1 & 4442 & 35 & 35 & 34 & 36 \\
\hline CP19 & 78,5 & 42,000 & 52,5 & 4522 & 43 & 42 & 44 & 43 \\
\hline CP20 & 79,2 & 39,200 & 48,6 & 4246 & 39 & 39 & 39 & 38 \\
\hline CP21 & 80,0 & 41,700 & 51,1 & 4752 & 44 & 42 & 42 & 47 \\
\hline CP22 & 80,1 & 42,200 & 51,7 & 4719 & 37 & 38 & 40 & 34 \\
\hline CP23 & 79,0 & 49,800 & 61,8 & 4487 & 40 & 41 & 40 & 40 \\
\hline CP24 & 79,1 & 34,100 & 42,3 & 4758 & 41 & 39 & 44 & 40 \\
\hline CP25 & 79,1 & 43,100 & 53,4 & 4752 & 37 & 40 & 38 & 34 \\
\hline CP26 & 79,1 & 36,500 & 45,3 & 4351 & 36 & 34 & 37 & 36 \\
\hline
\end{tabular}

Na sequência, os resultados experimentais foram comparados aos modelos apresentados no item 2 deste trabalho. Para o ensaio de velocidade de propagação da onda ultrassônica, utilizaram-se os modelos 1, 2, 3 e 4, como se observa na Figura 12 (MEHTA e MONTEIRO [13]), Figura 13 (VASCONCELOS e GIAMMUSSO [18]) e Figura 14 (PALACIOS [4] e MACHADO et al. [7]).

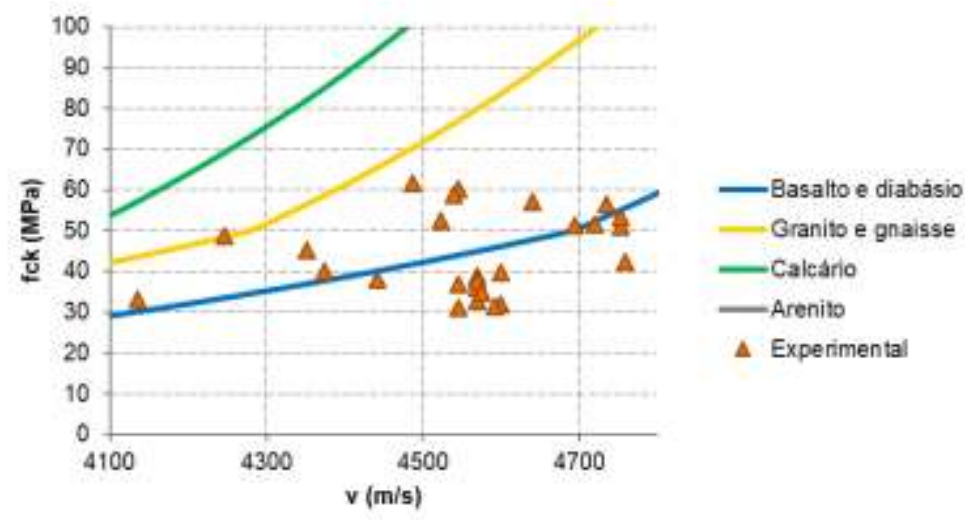

Figura 12: Comparação de resultados experimentais com curvas teóricas - Modelo 1 (Fonte: autores). 


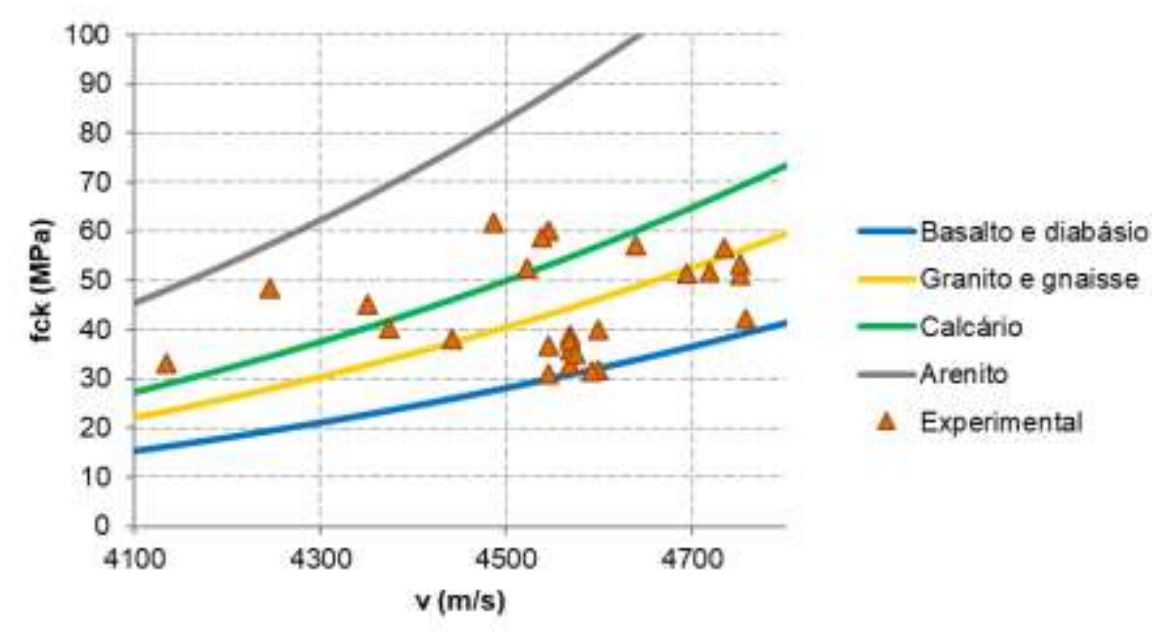

Figura 13: Comparação de resultados experimentais com curvas teóricas - Modelo 2 (Fonte: autores).

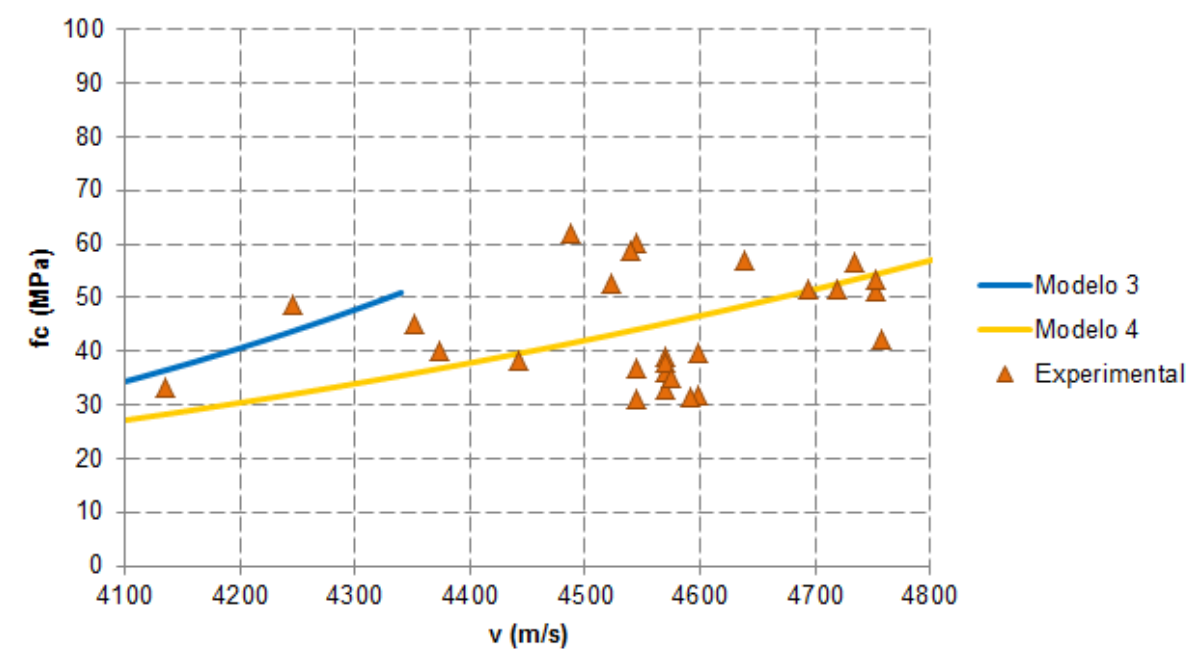

Figura 14: Comparação de resultados experimentais com curvas práticas - Modelos 3 e 4 (Fonte: autores).

Acerca do modelo 1, observa-se que os resultados experimentais se aproximam da curva teórica referente aos agregados graúdos basalto e diabásio. Estes dados, no entanto, não acordam com a realidade da Grande Vitória, onde os concretos são produzidos com agregados graúdos provenientes de granito e gnaisse. Quando comparados ao modelo 2, os resultados experimentais estabeleceram-se entre as curvas teóricas dos agregados graúdos basalto e diabásio, granito e gnaisse e calcário, e aproximaram-se, principalmente, da curva referente ao granito e gnaisse. Esta situação é mais usual que a anterior, uma vez que, como previamente abordado, na Grande Vitória utilizam-se com maior frequência estes tipos de rocha como agregados graúdos para concreto, segundo informações de concreteiras locais.

Ainda seguindo o critério visual, por fim, os dados experimentais são mais próximos às curvas empíricas. Por outro lado, cabe destacar que a restrição indicada pela autora [4] para uso da Equação (7) limita a análise comparativa dos resultados referente ao modelo 3, posto que somente duas das vinte e seis amostras avaliadas enquadram-se no intervalo em que os ajustes experimentais foram realizados.

Na sequência, a Figura 15 ilustra a comparação entre os resultados experimentais e os modelos sugeridos para o ensaio de esclerometria. 


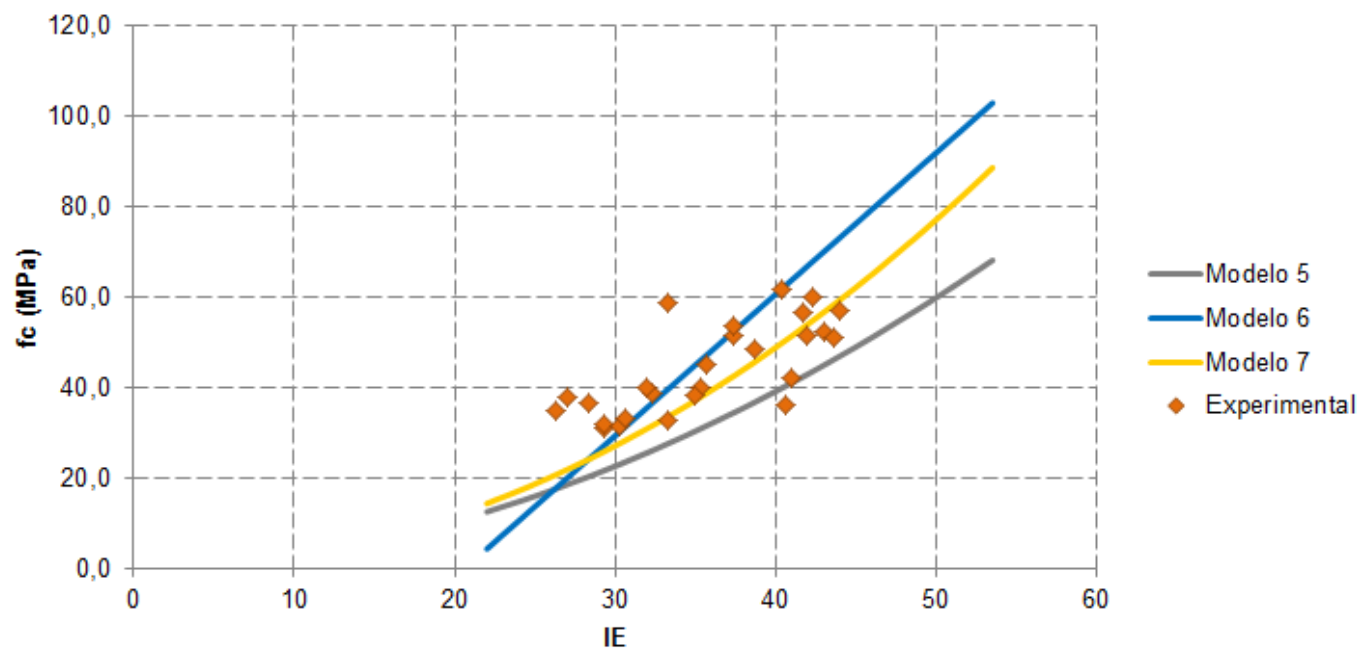

Figura 15: Comparação de resultados experimentais com curva teórica do ensaio de esclerometria (Fonte: autores).

Pode-se verificar que os resultados da análise apresentam pouca dispersão em relação a todos os modelos, uma vez que as resistências experimentais se aproximam das curvas analisadas. Do ponto de vista de projeto, a correlação do fabricante (modelo 5) está a favor da segurança, posto que, se um valor estimado atender aos requisitos e critérios de segurança, o elemento estrutural responderá com resistência superior às solicitações. O modelo 7, por sua vez, melhor se ajusta aos dados experimentais, apresentando tanto resultados superestimados como subestimados - em sua maioria, pela correlação. O modelo 6, por fim, superestima a maior parte dos valores avaliados, mas ainda assim permite a aproximação com dados experimentais, apesar de seu caráter linear.

A Tabela 3 e a Tabela 4 comparam estatisticamente os resultados teóricos, obtidos pelas correlações apresentadas, tomando como dados de entrada a velocidade de propagação de ondas ultrassônicas, massa específica dos corpos de prova e índice esclerométrico, com os resultados experimentais de resistência à compressão axial dos corpos de prova ensaiados. Para cada uma das abordagens, determinam-se os desvios entre resultados teóricos e experimentais $(\delta)$, a média dos desvios $\left(\delta_{\text {med }}\right)$, a média dos módulos dos desvios $\left(\left|\delta_{\text {med }}\right|\right)$ e o desvio padrão (s). Cabe ainda ressaltar que $\mathrm{f}_{\mathrm{c}, \mathrm{E}}$ denota a resistência à compressão proveniente do ensaio e $\mathrm{f}_{\mathrm{c}, \mathrm{T}}$ indica a resistência à compressão teórica, calculada com cabe na correlação analisada, teórica ou empírica. 
Tabela 3: Análise estatística das resistências teóricas com as resistências experimentais pelo ensaio de velocidade de propagação da onda ultrassônica (Fonte: autores).

\begin{tabular}{|c|c|c|c|c|c|c|c|c|c|c|}
\hline \multirow[t]{2}{*}{ ID } & \multirow{2}{*}{$\mathbf{f}_{\mathrm{c}, \mathrm{E}}(\mathrm{MPa})$} & \multirow{2}{*}{$v(m / s)$} & \multicolumn{2}{|c|}{ MODELO 1} & \multicolumn{2}{|c|}{ MODELO 2} & \multicolumn{2}{|c|}{ MODELO 3} & \multicolumn{2}{|c|}{ MODELO 4} \\
\hline & & & $\mathrm{f}_{\mathrm{c}, \mathrm{T}}(\mathrm{MPa})$ & $\delta(\%)$ & $\mathrm{f}_{\mathrm{c}, \mathrm{T}}(\mathrm{MPa})$ & $\delta(\%)$ & $f_{c, T}(\mathrm{MPa})$ & $\delta(\%)$ & $\mathbf{f}_{\mathrm{c}, \mathrm{T}}(\mathrm{MPa})$ & $\delta(\%)$ \\
\hline CP1 & 32,8 & 4569 & 78,4 & $139 \%$ & 43,9 & $34 \%$ & -- & -- & 45,2 & $38 \%$ \\
\hline CP2 & 31,1 & 4545 & 79,1 & $155 \%$ & 44,2 & $42 \%$ & -- & -- & 44,1 & $42 \%$ \\
\hline $\mathrm{CP} 3$ & 31,9 & 4599 & 87,4 & $174 \%$ & 48,2 & $51 \%$ & -- & -- & 46,6 & $46 \%$ \\
\hline CP4 & 38,9 & 4569 & 78,0 & $101 \%$ & 43,7 & $12 \%$ & -- & -- & 45,2 & $16 \%$ \\
\hline CP5 & 36,0 & 4569 & 70,5 & $96 \%$ & 40,0 & $11 \%$ & -- & -- & 45,2 & $26 \%$ \\
\hline CP6 & 37,8 & 4569 & 79,5 & $110 \%$ & 44,4 & $17 \%$ & -- & -- & 45,2 & $20 \%$ \\
\hline CP7 & 31,4 & 4592 & 86,4 & $175 \%$ & 47,7 & $52 \%$ & -- & -- & 46,2 & $47 \%$ \\
\hline CP8 & 34,9 & 4575 & 81,6 & $134 \%$ & 45,4 & $30 \%$ & -- & -- & 45,4 & $30 \%$ \\
\hline CP9 & 39,9 & 4599 & 84,1 & $111 \%$ & 46,6 & $17 \%$ & -- & -- & 46,6 & $17 \%$ \\
\hline CP10 & 33,2 & 4135 & 42,8 & $29 \%$ & 22,9 & $-31 \%$ & 36,47 & $10 \%$ & 28,3 & $-15 \%$ \\
\hline CP11 & 36,8 & 4545 & 76,3 & $108 \%$ & 42,8 & $17 \%$ & -- & -- & 44,1 & $20 \%$ \\
\hline CP12 & 51,4 & 4694 & 103,6 & $102 \%$ & 61,3 & $19 \%$ & -- & -- & 51,3 & $0 \%$ \\
\hline CP13 & 40,2 & 4374 & 46,8 & $17 \%$ & 28,0 & $-30 \%$ & -- & -- & 36,8 & $-8 \%$ \\
\hline CP14 & 56,5 & 4734 & 104,6 & $85 \%$ & 62,2 & $10 \%$ & -- & -- & 53,4 & $-6 \%$ \\
\hline CP15 & 57,1 & 4639 & 85,1 & $49 \%$ & 47,1 & $-17 \%$ & -- & -- & 48,5 & $-15 \%$ \\
\hline CP16 & 60,2 & 4545 & 67,2 & $12 \%$ & 38,3 & $-36 \%$ & -- & -- & 44,1 & $-27 \%$ \\
\hline CP17 & 58,7 & 4539 & 80,7 & $37 \%$ & 45,0 & $-23 \%$ & -- & -- & 43,8 & $-25 \%$ \\
\hline CP18 & 38,1 & 4442 & 60,3 & $58 \%$ & 34,9 & $-8 \%$ & -- & -- & 39,6 & $4 \%$ \\
\hline CP19 & 52,5 & 4522 & 79,6 & $51 \%$ & 44,4 & $-15 \%$ & -- & -- & 43,0 & $-18 \%$ \\
\hline CP20 & 48,6 & 4246 & 44,3 & $-9 \%$ & 24,3 & $-50 \%$ & 43,78 & $-10 \%$ & 32,0 & $-34 \%$ \\
\hline CP21 & 51,1 & 4752 & 108,4 & $112 \%$ & 65,8 & $29 \%$ & -- & -- & 54,3 & $6 \%$ \\
\hline CP22 & 51,7 & 4719 & 107,8 & $109 \%$ & 65,1 & $26 \%$ & -- & -- & 52,6 & $2 \%$ \\
\hline CP23 & 61,8 & 4487 & 65,4 & $6 \%$ & 37,5 & $-39 \%$ & -- & -- & 41,5 & $-33 \%$ \\
\hline CP24 & 42,3 & 4758 & 107,8 & $155 \%$ & 65,1 & $54 \%$ & -- & -- & 54,6 & $29 \%$ \\
\hline CP25 & 53,4 & 4752 & 107,9 & $102 \%$ & 65,2 & $22 \%$ & -- & -- & 54,3 & $2 \%$ \\
\hline \multirow[t]{4}{*}{ CP26 } & 45,3 & 4351 & 47,5 & $5 \%$ & 28,4 & $-37 \%$ & -- & -- & 35,9 & $-21 \%$ \\
\hline & & & $\delta_{\text {med }}$ & $85 \%$ & $\delta_{\text {med }}$ & $6 \%$ & $\delta_{\text {med }}$ & $0 \%$ & $\delta_{\text {med }}$ & $5 \%$ \\
\hline & & & $\left|\delta_{\text {med }}\right|$ & $86 \%$ & $\left|\delta_{\text {med }}\right|$ & $28 \%$ & $\left|\delta_{\text {med }}\right|$ & $10 \%$ & $\left|\delta_{\text {med }}\right|$ & $24 \%$ \\
\hline & & & $\mathbf{s}$ & $55 \%$ & $\mathbf{s}$ & $31 \%$ & $\mathbf{s}$ & $14 \%$ & $\mathbf{s}$ & $14 \%$ \\
\hline
\end{tabular}


Tabela 4: Análise estatística das resistências teóricas com as resistências experimentais pelo ensaio de esclerometria (Fonte: autores).

\begin{tabular}{|c|c|c|c|c|c|c|c|c|}
\hline \multirow{2}{*}{ ID } & \multirow{2}{*}{$\mathrm{f}_{\mathrm{c}, \mathrm{E}}(\mathrm{MPa})$} & \multirow{2}{*}{ IE } & \multicolumn{2}{|c|}{ MODELO 5} & \multicolumn{2}{|c|}{ MODELO 6} & \multicolumn{2}{|c|}{ MODELO 7} \\
\hline & & & $\mathrm{f}_{\mathrm{c}, \mathrm{T}}(\mathrm{MPa})$ & $\delta(\%)$ & $\mathrm{f}_{\mathrm{c}, \mathrm{T}}(\mathrm{MPa})$ & $\delta(\%)$ & $\mathrm{f}_{\mathrm{c}, \mathrm{T}}(\mathrm{MPa})$ & $\delta(\%)$ \\
\hline CP1 & 32,8 & 33 & 27,7 & $-15 \%$ & 39,85 & $22 \%$ & 33,7 & $3 \%$ \\
\hline CP2 & 31,1 & 29 & 21,7 & $-30 \%$ & 27,33 & $-12 \%$ & 26,0 & $-16 \%$ \\
\hline CP3 & 31,9 & 29 & 21,7 & $-32 \%$ & 27,33 & $-14 \%$ & 26,0 & $-19 \%$ \\
\hline CP4 & 38,9 & 32 & 26,2 & $-33 \%$ & 36,72 & $-6 \%$ & 31,7 & $-19 \%$ \\
\hline CP5 & 36,0 & 41 & 40,5 & $13 \%$ & 62,80 & $75 \%$ & 50,6 & $41 \%$ \\
\hline CP6 & 37,8 & 27 & 18,6 & $-51 \%$ & 20,03 & $-47 \%$ & 21,9 & $-42 \%$ \\
\hline CP7 & 31,4 & 30 & 23,2 & $-26 \%$ & 30,46 & $-3 \%$ & 27,8 & $-12 \%$ \\
\hline CP8 & 34,9 & 26 & 17,7 & $-49 \%$ & 17,94 & $-49 \%$ & 20,8 & $-40 \%$ \\
\hline CP9 & 39,9 & 32 & 25,7 & $-36 \%$ & 35,68 & $-11 \%$ & 31,0 & $-22 \%$ \\
\hline CP10 & 33,2 & 31 & 23,7 & $-29 \%$ & 31,50 & $-5 \%$ & 28,4 & $-14 \%$ \\
\hline CP11 & 36,8 & 28 & 20,4 & $-45 \%$ & 24,20 & $-34 \%$ & 24,2 & $-34 \%$ \\
\hline CP12 & 51,4 & 42 & 43,0 & $-16 \%$ & 66,98 & $30 \%$ & 54,1 & $5 \%$ \\
\hline CP13 & 40,2 & 35 & 31,0 & $-23 \%$ & 46,11 & $15 \%$ & 38,0 & $-5 \%$ \\
\hline CP14 & 56,5 & 42 & 42,4 & $-25 \%$ & 65,93 & $17 \%$ & 53,2 & $-6 \%$ \\
\hline CP15 & 57,1 & 44 & 47,0 & $-18 \%$ & 73,24 & $28 \%$ & 59,5 & $4 \%$ \\
\hline CP16 & 60,2 & 42 & 43,7 & $-27 \%$ & 68,02 & $13 \%$ & 54,9 & $-9 \%$ \\
\hline CP17 & 58,7 & 33 & 27,7 & $-53 \%$ & 39,85 & $-32 \%$ & 33,7 & $-43 \%$ \\
\hline CP18 & 38,1 & 35 & 30,4 & $-20 \%$ & 45,07 & $18 \%$ & 37,2 & $-2 \%$ \\
\hline CP19 & 52,5 & 43 & 45,0 & $-14 \%$ & 70,11 & $33 \%$ & 56,7 & $8 \%$ \\
\hline CP20 & 48,6 & 39 & 36,8 & $-24 \%$ & 56,54 & $16 \%$ & 45,7 & $-6 \%$ \\
\hline CP21 & 51,1 & 44 & 46,3 & $-9 \%$ & 72,19 & $41 \%$ & 58,5 & $15 \%$ \\
\hline CP22 & 51,7 & 37 & 34,4 & $-33 \%$ & 52,37 & $1 \%$ & 42,5 & $-18 \%$ \\
\hline CP23 & 61,8 & 40 & 39,8 & $-36 \%$ & 61,76 & $0 \%$ & 49,8 & $-19 \%$ \\
\hline CP24 & 42,3 & 41 & 41,1 & $-3 \%$ & 63,85 & $51 \%$ & 51,5 & $22 \%$ \\
\hline CP25 & 53,4 & 37 & 34,4 & $-36 \%$ & 52,37 & $-2 \%$ & 42,5 & $-20 \%$ \\
\hline CP26 & 45,3 & 36 & 31,5 & $-30 \%$ & 47,15 & $4 \%$ & 38,7 & $-14 \%$ \\
\hline & & & $\delta_{\text {med }}$ & $-27 \%$ & $\delta_{\text {med }}$ & $6 \%$ & $\delta_{\text {med }}$ & $-10 \%$ \\
\hline & & & $\left|\delta_{\text {med }}\right|$ & $26 \%$ & $\left|\delta_{\text {med }}\right|$ & $11 \%$ & $\left|\delta_{\text {med }}\right|$ & $10 \%$ \\
\hline & & & s & $3 \%$ & $\mathbf{s}$ & $15 \%$ & $\mathbf{s}$ & $6 \%$ \\
\hline
\end{tabular}


Para o ensaio de ultrassom, os resultados obtidos pela correlação teórica baseada em VASCONCELOS e GIAMMUSSO [18] são mais próximos dos resultados experimentais quando comparados à correlação baseada em MEHTA e MONTEIRO [13], uma vez que a média dos desvios para o primeiro caso foi de $6 \%$ contra $85 \%$ do segundo caso, mesmo que o desvio padrão indique certa dispersão dos dados em torno da curva analisada. Tomando por base a média dos desvios absolutos, observa-se que o primeiro caso desviou $28 \%$ contra $86 \%$ do segundo caso, reforçando a ideia de que relação entre os módulos de elasticidade estático e dinâmico apresentadas por VASCONCELOS e GIAMMUSSO [18] fornecem indicadores mais coerentes. Além disso, quando avaliados à luz do modelo empírico 4, os resultados supracitados são mais bem estimados, reflexo de diminuição dos desvios médios para $5 \%$ e $24 \%$ em módulo, além de um menor desvio padrão, o que indica menor dispersão dos dados amostrados. O modelo 3, embora tenha fornecido as melhores estatísticas, pode ser aplicado a 7\% dos corpos-de-prova ensaiados e, desse modo, não fornece resultados com sólidos e com boa margem de confiabilidade. As conclusões da Tabela 3 são exibidas através do gráfico de barras da Figura 16.

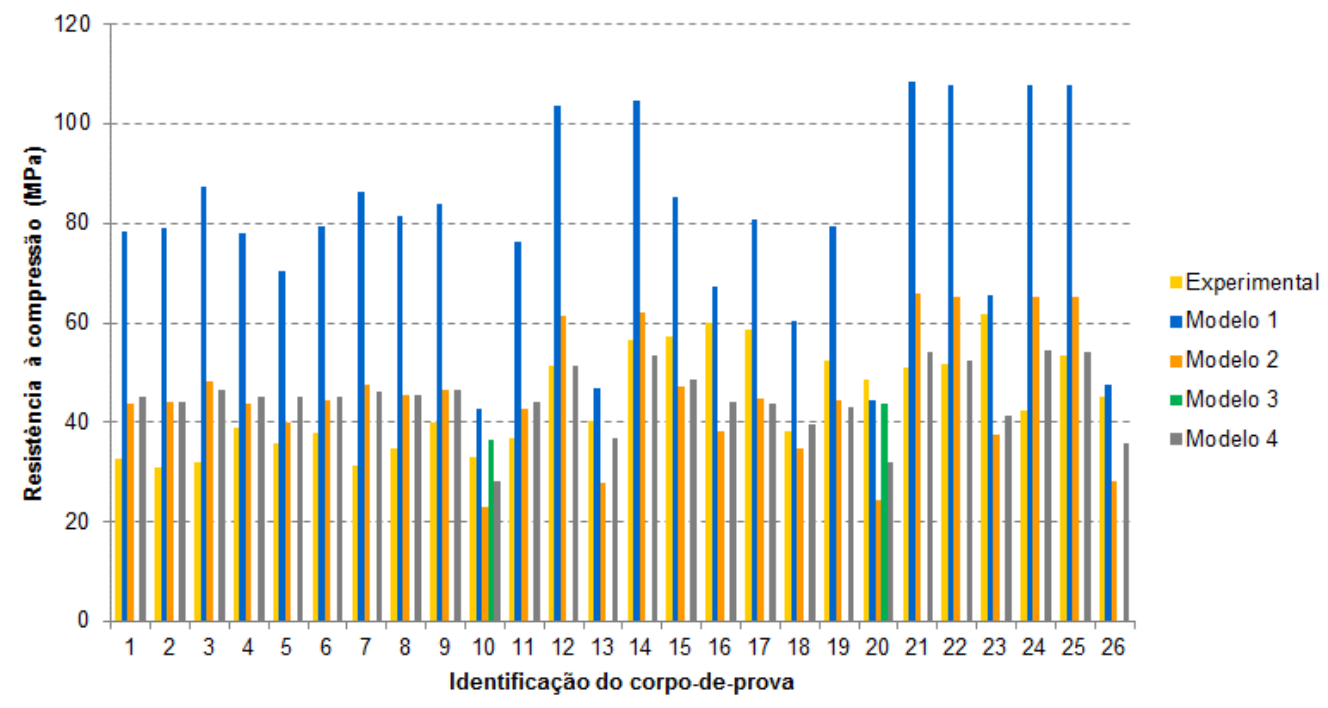

Figura 16: Comparativo entre resultados teóricos e experimentais para ensaio de ultrassom (Fonte: autores).

A Tabela 4, por sua vez, está representada através da Figura 17, permitindo realizar uma análise comparativa visual dos dados.

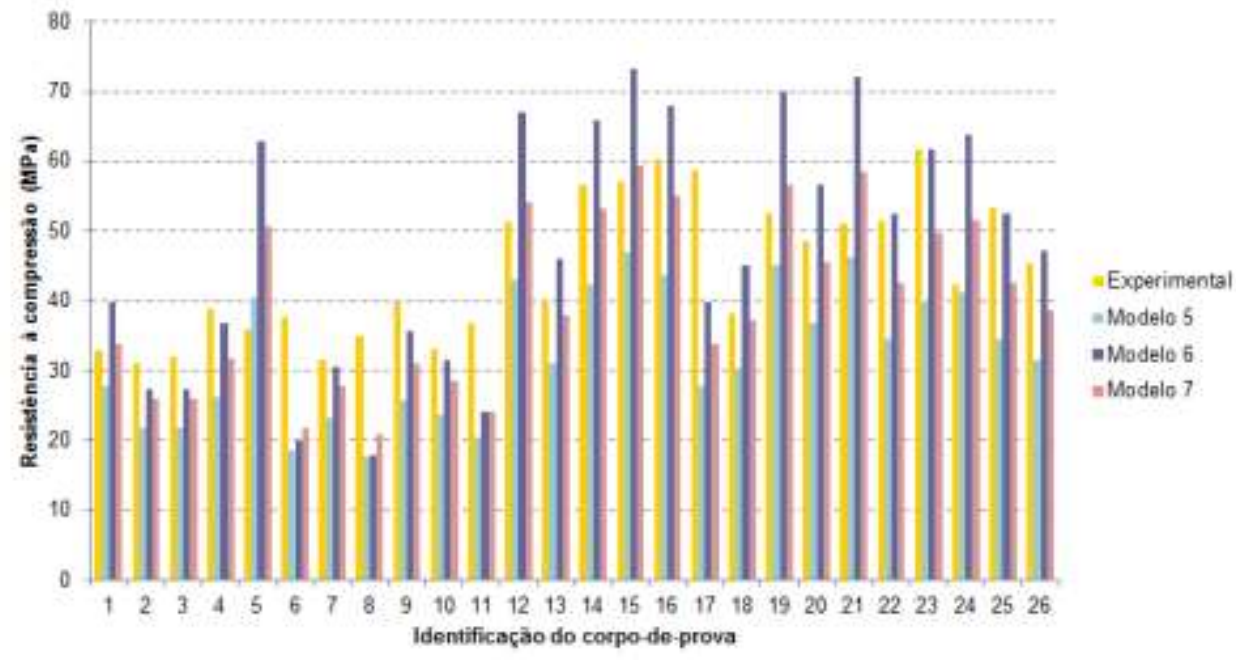

Figura 17: Comparativo entre resultados teóricos e experimentais para ensaio de esclerometria (Fonte: autores).

Para o ensaio de esclerometria, com média dos desvios de $-27 \%$, média dos desvios absolutos de $26 \%$ e desvio padrão de $15 \%$ avaliados à luz do modelo 5, a análise mostra que os resultados são pouco dispersos 
quando se comparam as resistências à compressão obtidas pelo ensaio de compressão axial com aquelas provenientes da curva teórica do fabricante do esclerômetro, com caráter conservador. Os demais modelos, obtidos para condições diferentes daquelas utilizadas neste estudo, ainda fornecem resultados satisfatórios, uma vez que a média dos desvios absolutos fica próxima a $10 \%$. No entanto, o modelo 7 , baseado no ajuste não linear dos dados experimentais proposto por MACHADO et al. [7] fornece as melhores aproximações para as resistências à compressão do conjunto em estudo, um vez que se observa pouca dispersão no conjunto (6\%), somado à menor média dos desvios absolutos.

Por fim, a análise geral dos valores sugere que o ensaio de avaliação da dureza superficial por meio do esclerômetro de reflexão subestimam a resistência média à compressão do concreto para o modelo 5, conforme Figura 17, e superestima no tocante aos demais modelos. O ensaio de velocidade de propagação de ondas ultrassônicas no concreto, por outro lado, superestimou as resistências médias dos corpos-de-prova de concreto, como observado pelos desvios médios para todos os modelos, à exceção do $3^{\circ}$, na Tabela 3 .

A ampla dispersão nos resultados obtidos pelos dois ensaios, quando comparados aos modelos propostos, está associada à variabilidade natural das propriedades do concreto. Os parâmetros fundamentais para a dosagem do concreto, tais como relação água/cimento, tipo de cimento, presença e tipos de aditivos e adições, idade e tipo de cimento, não foram controlados nos experimentos. No entanto, fica evidente a dependência entre resistência à compressão e parâmetros medidos através de ensaios não destrutivos, fato também verificado por PALACIOS [4] e MACHADO et al. [7]. Ambos os autores realizaram ajuste experimental de dados com coeficientes de determinação para as regressões variando de 0,64 a 0,679 para velocidade de propagação da onda ultrassônica e variando de 0,814 a 0,899 para o índice esclerométrico, valores que sugerem interdependência marcante entre as variáveis testadas (ASSIS apud PALACIOS [22]).

\section{CONCLUSÕES}

Este trabalho teve como objetivo a validação dos resultados dos ensaios não destrutivos de esclerometria e de ultrassom na avaliação da resistência à compressão de concretos, confrontando parâmetros experimentais com aqueles existentes em trabalhos anteriores e em normas técnicas vigentes. Comparando tais resultados teóricos com experimentais, foi possível testar a acurácia das correlações teóricas e empíricas na determinação do parâmetro de interesse: a resistência à compressão.

Com base na literatura, a resistência do concreto tem conexão direta com a velocidade de propagação de ondas ultrassônicas quando comparadas as formulações presentes na ABNT NBR 6118 [15] e ASTM C597-02 [21], valendo-se de relações entre os módulos de elasticidade dinâmico e estático segundo MEHTA e MONTEIRO [13] e VASCONCELOS e GIAMMUSSO [18]. Os resultados para concretos da Grande Vitória apresentaram grande variabilidade em relação à primeira formulação [13], aproximando-se de uma curva típica de concretos produzidos com basalto e diabásio, pouco usual na região de estudo. Desse modo, fica evidente que módulos de elasticidade dinâmico e estático não podem ser tomados iguais. Por outro lado, a segunda correlação [15] forneceu resultados mais próximos dos experimentais, do ponto de vista prático, com desvio das leituras em relação à média de $6 \%$ e desvio padrão de $31 \%$.

Além disso, pode-se notar certa discrepância nos resultados teóricos quando o tipo de agregado é levado em conta. As curvas do gráfico de velocidade de propagação da onda ultrassônica versus resistência sugerem um maior parâmetro de resistência quando se utiliza na composição do concreto o arenito, rocha sedimentar, com menor resistência dentre todas as demais abordadas pela ABNT NBR 6118 [15]. Tal fato indica uma incoerência nos resultados apresentados, os quais devem ser atentamente analisados quando as correlações propostas forem empregadas em projeto.

É importante destacar, ainda, que o ensaio de esclerometria apresentou o menor dos desvios padrão quando confrontado aos experimentos de ultrassom, mostrando-se o método mais conservador para a finalidade à qual se destina. Entretanto, a variabilidade dos dados do conjunto amostral indicou a não aderência dos resultados aos modelos teóricos expostos, dada a heterogeneidade do concreto e de suas propriedades. Variáveis como idade do concreto e procedimentos de moldagem e cura dos corpos-de-prova, por exemplo, não tiveram sua influência analisada neste estudo. O emprego das correlações teóricas via ultrassom para obtenção da resistência média ou característica do concreto à compressão, nas condições em que foram avaliadas, produzem dados dispersos e que se afastam dos referenciais experimentais.

Por fim, a correlação dos dados de laboratórios com correlações empíricas existentes na literatura, traduzidas pelos modelos 3, 4, 6 e 7, indica a clara dependência entre parâmetros aferidos em ensaios destrutivos e não destrutivos, porém com dispersão. Desse modo, conclui-se que estimar a resistência à compressão do concreto através de leituras de índice esclerométrico ou velocidade de propagação de ondas ultrassônicas é uma realidade na Engenharia. Por outro lado, cabe ao projetista utilizar equações empíricas ajustadas a par- 
tir de conjuntos representativos e com características similares ao concreto em análise.

\section{AGRADECIMENTOS}

Os autores agradecem à Universidade Federal do Espírito Santo, ao Instituto Federal do Espírito Santo Campus Vitória, ao HUCAM - Hospital Universitário Cassiano Antônio de Moraes, à CAPES, ao CNPq e a todas as demais instituições que tornaram possível esta pesquisa pela doação de corpos-de-prova para ensaios.

\section{BIBLIOGRAFIA}

[1] ASSOCIAÇÃO BRASILEIRA DE NORMAS TÉCNICAS, NBR 5739: Concreto - Ensaio de compressão de corpos-de-prova cilíndricos. Rio de Janeiro, 2018.

[2] ASSOCIAÇÃO BRASILEIRA DE NORMAS TÉCNICAS, NBR 5738: Concreto - Procedimento para moldagem e cura de corpos-de-prova. Versão corrigida:2016, Rio de Janeiro, 2015.

[3] ASSOCIAÇÃO BRASILEIRA DE NORMAS TÉCNICAS, NBR 12655: Concreto de cimento Portland Preparo, controle, recebimento e aceitação - Procedimento. Versão corrigida:2015, Rio de Janeiro, 2015.

[4] PALACIOS, M. P. G., "Emprego de ensaios não destrutivos e de extração de testemunhos na avaliação da resistência à compressão do concreto", Dissertação de M.Sc., FT/UnB, Brasília, 2012.

[5] TAY e TAMT (1995) apud PALACIOS M. P. G., "Emprego de ensaios não destrutivos e de extração de testemunhos na avaliação da resistência à compressão do concreto", Dissertação de M.Sc, FT/UnB, Brasília, Brasil, 2012.

[6] CÂMARA, E., "Avaliação da resistência à compressão de concretos utilizados na Grande Florianópolis através de ensaios não-destrutivos", Dissertação de M.Sc., PPGEC/UFSC, Florianópolis, SC, Brasil, 2006.

[7] MACHADO, M.D., SHEHATA, L. C. D., SHEHATA, I. A. E. M., "Curvas de Correlação para Caracterizar Concretos Usados no Rio de Janeiro por Meio de Ensaios Não Destrutivos", Revista Ibracon de Estruturas e Materiais, v.2, n.2, pp. 100-123, Junho de 2009.

[8] IRRIGARAY, M. P. A., PINTO, R. C. A., PADARATZ, I. J., "Um novo procedimento para estimar a resistência à compressão do concreto pelo método VPU”, Revista Ibracon de Estruturas e Materiais, v.9, n.3, pp. 395-402, Junho de 2016.

[9] ASSOCIAÇÃO BRASILEIRA DE NORMAS TÉCNICAS, NBR 8802: Concreto Endurecido - Determinação da velocidade de propagação de onda ultrassônica, Rio de Janeiro, 2019.

[10] ASSOCIAÇÃO BRASILEIRA DE NORMAS TÉCNICAS, NBR 7584: Concreto Endurecido - Avaliação da dureza superficial pelo esclerômetro de reflexão - Método de ensaio, Rio de Janeiro, 2012.

[11] ARAÚJO, J.M., Curso de Concreto Armado, $3^{\mathrm{a}}$ ed., Rio Grande do Sul, Editora Dunas, 2010.

[12] PACHECO, J., BILESKY, P., MORAIS, T. R., et al., "Considerações sobre o módulo de elasticidade do concreto", In: 56 Congresso Brasileiro do Concreto, Natal, Outubro de 2014.

[13] MEHTA, K.P., MONTEIRO, P.J.M., Concreto: microestrutura, propriedades e materiais, $3^{\mathrm{a}}$ ed., São Paulo, Editora Pini, 2008.

[14] SANTOS, A. M., CABRAL, L. M. C., MONTEIRO, E. B., et al., "Analise do módulo de elasticidade estático e dinâmico para diferentes dosagens de concreto", In: $55^{\circ}$ Congresso Brasileiro do Concreto, Gramado, Outubro de 2013.

[15] ASSOCIAÇÃO BRASILEIRA DE NORMAS TÉCNICAS, NBR 6118: Projeto de estruturas de concreto - procedimento, Rio de Janeiro, 2014.

[16] BENETTI, J.K, "Avaliação do módulo de elasticidade dinâmico de concreto produzido com agregado graúdo reciclado de concreto", Dissertação de M.Sc., Programa de Pós-graduação em Engenharia Civil Unisinos, São Leopoldo, RS, Brasil, 2012.

[17] ASSOCIAÇÃO BRASILEIRA DE NORMAS TÉCNICAS, NBR 8522: Concreto - Determinação dos módulos estáticos de elasticidade e de deformação à compressão, Rio de Janeiro, 2017.

[18] Artigos, PORTAL TQS. VASCONCELOS, A. C.; GIAMMUSSO, S. E., TQS, http://www.tqs.com.br/suporte-e-servicos/biblioteca-digital-tqs/89/199. Acessado em 09 de julho de 2018.

[19] BRITISH STANDARD INSTITUTION, CP110: Code of practice for the structural use of concrete, 1972. 
[20] SOUZA, J. D., DE LA TORRE, E. M., KOSLOSKI, F., et al., "Obtenção da resistência à compressão do concreto de viadutos localizados na região de Curitiba por métodos de ensaios não destrutíveis: esclerometria e ultrassom", In: $44^{a}$ Reunião Anual de Pavimentação e $18^{\circ}$ Encontro Nacional de Conservação Rodoviária, Foz do Iguaçu, Agosto de 2015.

[21] AMERICAN SOCIETY FOR TESTING AND MATERIALS, C 597-02: Standard Test Method for Pulse Velocity Through Concrete, 2 ed., West Conshohocken, ASTM International, 2002.

[22] ASSIS (2011) apud PALACIOS M. P. G., "Emprego de ensaios não destrutivos e de extração de testemunhos na avaliação da resistência à compressão do concreto", Dissertação de M.Sc, FT/UnB, Brasília, Brasil, 2012.

\section{ORCID}

Lucas Fadini Favarato

Carlos Vinícius Soares do Rosário

João Pedro de Carvalho Alzuguir

Matheus Abreu Kerkoff

Tarek Zogheib Aoun

Geilma Lima Vieira https://orcid.org/0000-0003-4793-6722

https://orcid.org/0000-0001-5432-8771

https://orcid.org/0000-0002-4999-4777

https://orcid.org/0000-0002-8796-6793

https://orcid.org/0000-0003-3567-3187

https://orcid.org/0000-0001-6148-3307 